The Astrophysical Journal SupPLEMENT SERIES, 90:649-667, 1994 February

(c) 1994. The American Astronomical Sociely. All rights reserved. Printed in U.S.A.

\title{
ENERGETIC-PARTICLE ABUNDANCES IN IMPULSIVE SOLAR FLARE EVENTS
}

\author{
D. V. REAMES \\ Laboratory for High Energy Astrophysics, Code 661, NASA/Goddard Space Flight Center, Greenbelt, MD 20771 \\ J. P. MEYER ${ }^{1}$ \\ Laboratory for High Energy Astrophysics, Code 665, NASA, Goddard Space Flight Center, Greenbelt, MD 20771;' \\ and Service d'Astrophysique, CE-Saclay, 91191 Gif-sur-Yvette, France \\ AND \\ T. T. VON ROSENVINGE \\ Laboratory for High Energy Astrophysics, Code 661, NASA/Goddard Space Flight Center, Greenbelt, MD 20771 \\ Received 1993 March 1; accepted 1993 June I
}

\begin{abstract}
We report on the abundances of energetic particles from impulsive solar flares, including those from a survey of $228{ }^{3} \mathrm{He}$-rich events, with ${ }^{3} \mathrm{He} /{ }^{4} \mathrm{He}>0.1$, observed by the ISEE 3 spacecraft from 1978 August through 1991 April. The rate of occurrence of these events corresponds to $\sim 1000$ events $\mathrm{yr}^{-1}$ on the solar disk at solar maximum. Thus the resonant plasma processes that enhance ${ }^{3} \mathrm{He}$ and heavy elements are a common occurrence in impulsive solar flares. To supply the observed fluence of ${ }^{3} \mathrm{He}$ in large events, the acceleration must be highly efficient and the source region must be relatively deep in the atmosphere at a density of more than $10^{10}$ atoms $\mathrm{cm}^{-3} \cdot{ }^{3} \mathrm{He} /{ }^{4} \mathrm{He}$ may decrease in very large impulsive events because of depletion of ${ }^{3} \mathrm{He}$ in the source region.

The event-to-event variations in ${ }^{3} \mathrm{He} /{ }^{4} \mathrm{He}, \mathrm{H} /{ }^{4} \mathrm{He}, e / p$, and $\mathrm{Fe} / \mathrm{C}$ are uncorrelated in our event sample. Abundances of the elements show a pattern in which, relative to coronal composition, ${ }^{4} \mathrm{He}, \mathrm{C}, \mathrm{N}$, and $\mathrm{O}$ have normal abundance ratios, while $\mathrm{Ne}, \mathrm{Mg}$, and $\mathrm{Si}$ are enhanced by a factor $\sim 2.5$ and $\mathrm{Fe}$ by a factor $\sim 7$. This pattern suggests that elements are accelerated from a region of the corona with an electron temperature of $\sim 3-5 \mathrm{MK}$, where elements in the first group are fully ionized $(Q / A=0.5)$, those in the second group have two orbital electrons $(Q / A \sim 0.43)$, and $\mathrm{Fe}$ has $Q / A \sim 0.28$. Ions with the same gyrofrequency absorb waves of that frequency and are similarly accelerated and enhanced. Further stripping may occur after acceleration as the ions begin to interact with the streaming electrons that generated the plasma waves.
\end{abstract}

Subject headings: Sun: abundances — Sun: flares — Sun: particle emission

\section{INTRODUCTION}

Energetic-particle abundances have been found to provide a key signature that can distinguish particle populations from a variety of acceleration sources at the Sun and throughout the heliosphere. Particles from explosive solar events fall into two well-defined classes with greatly different composition (see Reames 1990, 1993 and references therein). These event classes are usually described as "impulsive" and "gradual" in reference to the timescale of the accompanying soft X-ray flare. The gradual or long-duration X-ray events are associated with coronal mass ejections (CMEs) (Sheeley et al. 1975; Pallavicini, Serio, \& Vaiana 1977) that can produce coronal and interplanetary shock waves (Sheeley et al. 1984; see Kahler 1992). Energetic particles from gradual events are dominated by protons, but the abundances of the elements $\mathrm{C}-\mathrm{Fe}$ are simply related to the corresponding abundances in the solar corona (Meyer 1985a, b, 1991, 1993a, b; Breneman \& Stone 1985; Stone 1989; Reames 1992). These particles are seen over a wide range of solar longitudes and have extended time profiles that can last for days (Reames 1993). The elements are observed in ionization states similar to those found in the solar wind, corresponding to an ambient coronal temperature of $\sim 2$

\footnotetext{
' NAS/NRC Senior Research Associate.
}

MK (Klecker et al. 1984; Luhn et al. 1984, 1985, 1987). Kahler et al. (1984) found that $96 \%$ of large proton events had associated CMEs, and it is likely that CME-associated shocks accelerate particles from the ambient material in the corona and solar wind as they expand throughout a large part of the heliosphere. Most of the major proton events involve gradual flares. Thus, one of the surprises of recent years is that particles in these events do not come from the solar flare at all but rather come from the CME-driven shock (see Reames 1993).

Impulsive events are usually dominated by electrons and have $\mathrm{H} /{ }^{4} \mathrm{He}$ ratios that are comparatively low, but they are best characterized by ${ }^{3} \mathrm{He} /{ }^{4} \mathrm{He}$ ratios that are frequently 3 or 4 orders of magnitude larger than the corresponding ratio in the solar atmosphere and solar wind where ${ }^{3} \mathrm{He} /{ }^{4} \mathrm{He} \sim 5 \times 10^{-4}$. Accompanying enhancements of heavier elements are typified by $\mathrm{Fe} / \mathrm{O} \sim 1$ versus $\mathrm{Fe} / \mathrm{O} \sim 0.1$ or less in gradual events. Particles are observed from impulsive flares in a narrow range of western solar longitudes that are magnetically well connected to the observer (Reames 1993). Particles usually stream outward from these events in a few hours, depending upon velocity (Reames, von Rosenvinge, \& Lin 1985; Mason et al. 1989). The energetic ions in these events are highly ionized. Fe has a mean charge of $20.5 \pm 1.2$ (Luhn et al. 1987) that was interpreted in terms of ionization in a flare plasma with electron temperatures higher than $10 \mathrm{MK}$ ( $>1 \mathrm{keV}$ electrons). 
The abundance enhancements are generally believed to result from selective heating by wave-particle interactions in the flare plasma (see reviews by Ramaty et al. 1980; Kocharov \& Kocharov 1984; Melrose 1990).

Solar ${ }^{3} \mathrm{He}$-rich events were first observed by Hsieh \& Simpson (1970), and the related heavy-ion enhancements in the events were first reported by Hurford et al. (1975) (see Reames 1990 and references therein). Owing to the limited sensitivity of instruments used during the 1970 s, only a small number of relatively large events were observed, hence they were thought to involve rare conditions in the flare plasma. More sensitive instruments launched in 1978 began to record more ${ }^{3} \mathrm{He}$-rich events, and these events were associated with scatter-free solar electron events (Reames et al. 1985), with kilometric type III radio bursts (Reames \& Stone 1986) and with impulsive hard and soft X-ray events on the Sun (Reames et al. 1988). Unlike the large proton events, ${ }^{3} \mathrm{He}$-rich events were rarely accompanied by CMEs (Kahler et al. 1985). It is now generally believed that ${ }^{3} \mathrm{He}$-rich, Fe-rich ions are a common property of all impulsive solar flares in which ions are accelerated. In fact, these same abundances have recently been reported for the energetic ions that interact inside flare loops to produce the observed spectrum of broad gamma-ray lines (Murphy et al. 1991).

In this paper we report on the properties of particles from impulsive flares, including the results of a comprehensive study of ${ }^{3} \mathrm{He}$-rich events observed on the ISEE 3/ICE spacecraft during the period from 1978 August 15 through 1991 April 27. An earlier study by Mason et al. (1986) reported abundances in $66{ }^{3} \mathrm{He}$-rich periods from 1978 August to 1982 July using a different instrument on the same spacecraft. A different sort of event sample that included both impulsive and gradual flare events was derived from studies of solar electron events (Reames, Cane, \& von Rosenvinge 1990).

\section{OBSERVATIONS AND ANALYSIS}

\subsection{Instrumentation}

All of the abundance measurements reported here were made using the two very low energy telescopes (VLETs) of the Goddard Space Flight Center Experiment (von Rosenvinge et al. 1978) flown aboard the ISEE 3/ICE spacecraft. From launch in 1978 August until 1982 September, the spacecraft was in halo orbit about the sunward L1 libration point, 240 Earth radii from Earth. Following several excursions into the geomagnetic tail region during 1983, the spacecraft began to move ahead of Earth in solar orbit at a rate of about 0.2 $\mathrm{AU} \mathrm{yr}^{-1}$.

Each VLET (von Rosenvinge et al. 1978) consists of two coaxial silicon surface-barrier detectors, D1 and D2, $2 \mathrm{~cm}^{2}$ in area by $\sim 15 \mu \mathrm{m}$ thick, arranged to define a $50^{\circ}$ opening cone. These are followed by larger $300 \mu \mathrm{m}$ thick detectors, $\mathrm{E}$ and $\mathrm{F}$, that serve as energy collector and anticoincidence shield, respectively. Typical response of the telescopes to ${ }^{3} \mathrm{He}$ and ${ }^{4} \mathrm{He}$ isotopes was shown by Reames et al. (1985). In Figure 1 we show the response of a VLET to ions in the C-Fe region for particles that stop in the DI or in the E detector. Each symbol
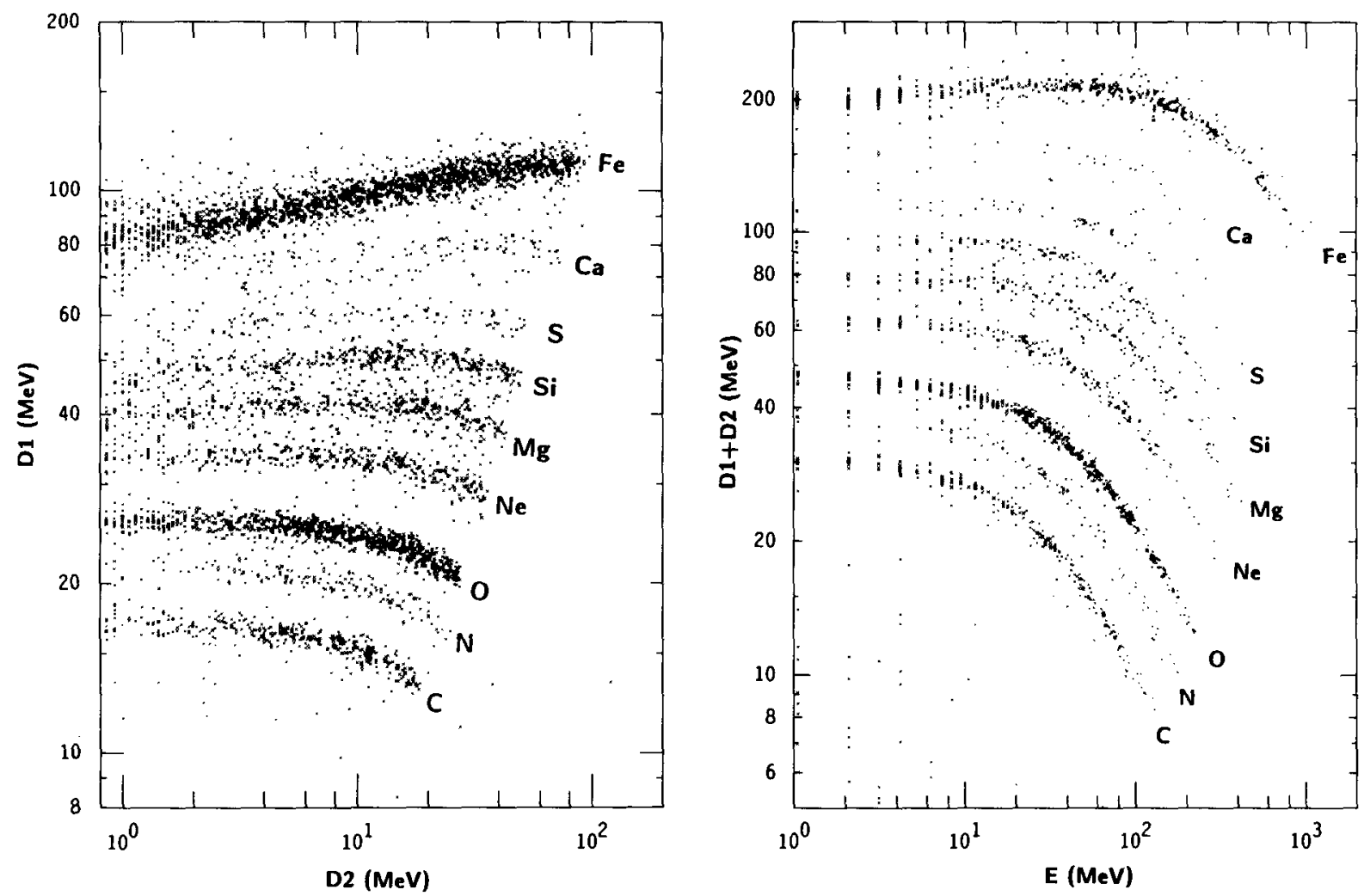

FIG. 1.-Response of an ISEE 3 VLET telescope to elements from C through Fe summed over all ${ }^{3}$ He-rich events during the $12.7 \mathrm{yr}$ study period (see text). The left-hand and right-hand panels show ions that stop in the D2 and E detectors, respectively. 
is one ion, and the tracks of the dominant elements are indicated in the figure. Figure 1 attests to the stability of the VLET as well as its resolution, since the figure includes all of the heavy ions that entered the telescope during all of the ${ }^{3} \mathrm{He}$-rich events during the $12.7 \mathrm{yr}$ observation period.

\section{2. ${ }^{3} \mathrm{He}$-rich Event Identification}

${ }^{3} \mathrm{He}$-rich events were located by scanning 2 and $8 \mathrm{hr}$ averaged intensities of 1.3-1.6 MeV amu ${ }^{-1}{ }^{3} \mathrm{He}$ and ${ }^{4} \mathrm{He}$ for times when ${ }^{3} \mathrm{He} /{ }^{4} \mathrm{He}$ might be greater than 0.1 . Consecutive time periods were grouped into event periods, and multiple individual events were then distinguished if they were clearly evident within a period. The average ${ }^{3} \mathrm{He}$ intensities of these candidate events were corrected for a $4 \%$ resolution spillover from neighboring ${ }^{4} \mathrm{He}$. In consideration of this spillover, the resulting ${ }^{3} \mathrm{He} /{ }^{4} \mathrm{He}$ ratio was required to be greater than 0.1 and to remain above the resolution background when ${ }^{3} \mathrm{He}$ was decreased by 2 standard deviations and ${ }^{4} \mathrm{He}$ was increased by 2 standard deviations. Notice that the effect of the resolution background is only important when ${ }^{3} \mathrm{He} /{ }^{4} \mathrm{He}$ is low. The ${ }^{3} \mathrm{He}$ background from other sources (e.g., cosmic-ray fragmentation) is negligible; it is estimated to be less than 1 particle per week.

For the $228{ }^{3} \mathrm{He}$-rich events resulting from these criteria, we show in Figure 2 the distribution of the observed ${ }^{3} \mathrm{He} /{ }^{4} \mathrm{He}$

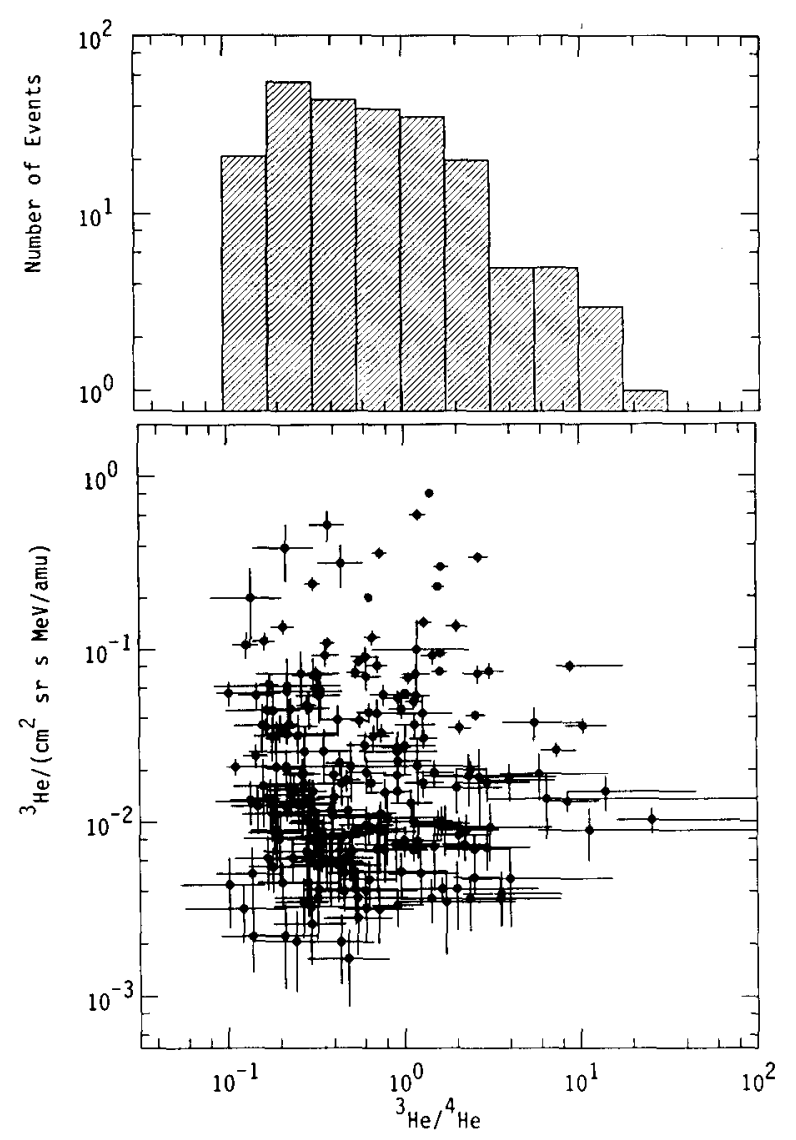

Fig. 2.-Intensity of $1.3-1.6 \mathrm{MeV}$ amu ${ }^{-1}{ }^{3} \mathrm{He}$ vs. ${ }^{3} \mathrm{He} /{ }^{4} \mathrm{He}$ (lower panel) and the distribution of the ${ }^{3} \mathrm{He} /{ }^{4} \mathrm{He}$ ratio (upper panel) for the 228 events. ratios and the ${ }^{3} \mathrm{He}$ intensity versus this ratio. It is probable that the slight rollover in the distribution near the ${ }^{3} \mathrm{He} /{ }^{4} \mathrm{He}=0.1$ boundary results from the event selection criteria. It is also likely that many events lie just below this boundary. From the electron event study of Reames et al. (1990), just over half of the Fe-rich electron events had ${ }^{3} \mathrm{He} /{ }^{4} \mathrm{He}>0.1$. Among the events listed in the review by Ramaty et al. (1980), about $80 \%$ have ${ }^{3} \mathrm{He} /{ }^{4} \mathrm{He}>0.1$.

With the large sample of ${ }^{3} \mathrm{He}$-rich events there is an impetus to revisit the associations with radio, optical, and X-ray observations of flares. In late 1983, however, the ISEE 3 spacecraft began to move ahead of Earth in solar orbit, and, by the time of the onset of the new solar cycle in 1989, the spacecraft was magnetically connected to solar longitudes far behind the west limb. This makes it impossible to correlate the particle observations with ground-based or near-Earth observations of flares. For this reason we have been unable to extend the correlation studies and have focused instead on the information provided by the particles themselves.

\subsection{Event Sample, Reference Compositions, and Techniques for Heavy-Element Analysis}

We have studied element abundances observed by the ISEE 3 instrument in the $1.9-2.8 \mathrm{MeV} \mathrm{amu}^{-1}$ region, which provides the best statistical accuracy. In all cases the abundances are determined from fluences, integrated over the duration of the event. The sample of events we have selected for analysis comprises three groups of events:

1. A group of $121{ }^{3} \mathrm{He}$-rich impulsive events with measurable heavy-element abundances, from the $228{ }^{3} \mathrm{He}$-rich events in this study. We recall that these events have been selected for observed ${ }^{3} \mathrm{He} /{ }^{4} \mathrm{He}$ ratios greater than 0.10 (Fig. 2), which corresponds to excess factors higher than 200 with respect to solar wind material. These events are depicted by filled circles in Figures 3 and 8-13.

2. A group of 18 events associated with impulsive flares on the Sun, but in which no ${ }^{3} \mathrm{He}$ enhancement greater than 0.1 could be observed. These events have further been selected from those studied by Reames et al. (1990) for their short $\mathrm{X}$-ray duration and for their Fe-richness $(\mathrm{Fe} / \mathrm{C}>1.5$ times coronal). The lack of observed ${ }^{3} \mathrm{He}$ enhancement only implies an enhancement less than 200 relative to the corona or solar wind, leaving the door still wide open for quite large enhancements. The motivation for including these events is that many of them are relatively large events with well-determined abundances. It is well known that ${ }^{3} \mathrm{He} /{ }^{4} \mathrm{He}$ decreases in large events (Reames et al. 1988), probably because most of the ${ }^{3} \mathrm{He}$ in the source volume has been accelerated (Reames 1993). Furthermore, recall that the magnitude of the Fe and of the ${ }^{3} \mathrm{He}$ enhancements are known not to be correlated in ${ }^{3} \mathrm{He}$-rich events (Mason et al. 1986; Van Hollebeke, McDonald, \& Meyer 1990). Figure 3, in which these events have been singled out by open circles, shows that they definitely seem to belong to the same population as the bona fide ${ }^{3} \mathrm{He}$-rich events rather than to the gradual event population. These 18 events are, of course, less safely ascertained as pure impulsive events than those in which ${ }^{3} \mathrm{He}$ could actually be observed. In Figures 8-13 we have plotted them with a symbol (solid square) that differs slightly from that of bona fide ${ }^{3} \mathrm{He}$-rich events (solid circle). 


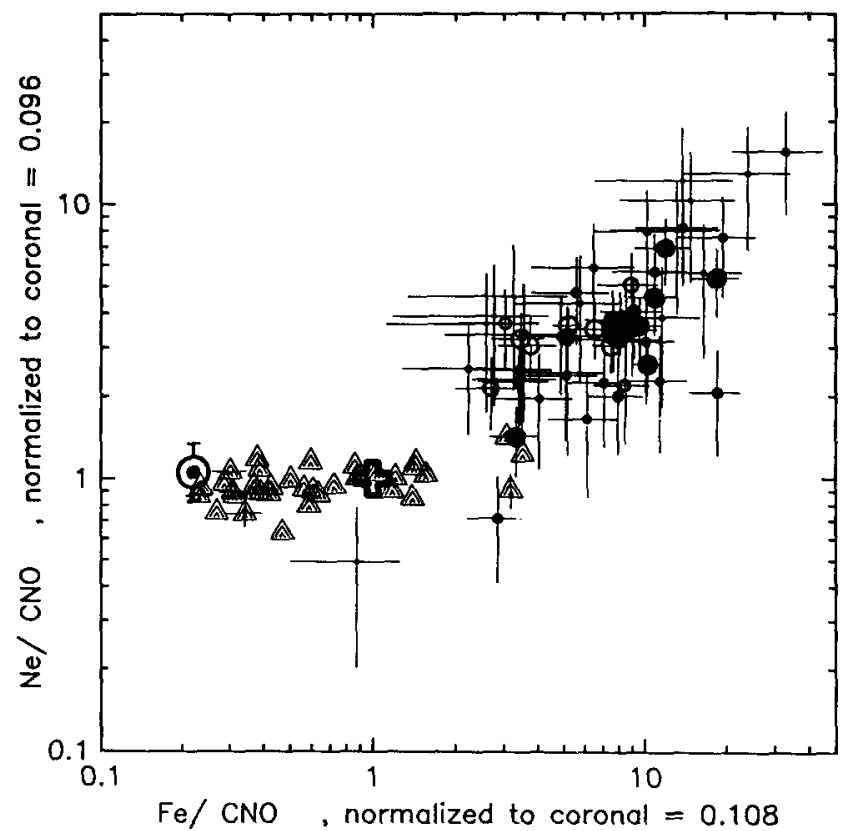

Fig. 3.-Correlation plot of $\mathrm{Ne} / \mathrm{CNO}$ as a function of the $\mathrm{Fe} / \mathrm{CNO}$ from ${ }^{3} \mathrm{He}$-rich events (filled circles), from other impulsive events (open circles; see text), and from large proton events (triangles). The size of the symbols varies inversely with the statistical errors in order to emphasize the most accurate measurements. Photospheric and coronal abundances are shown by a large circle and a large plus sign, respectively. The plot shows that the impulsive events in which ${ }^{3} \mathrm{He}$ could not be observed belong to the same class as ${ }^{3} \mathrm{He}$-rich events.

3. The 36 large, gradual, proton events discussed in detail by Cane, Reames, \& von Rosenvinge (1991), hereafter denoted "gradual events." These events, shown only for comparison, are depicted by triangles in Figures 3, 8, and 13.

The adopted photospheric and coronal reference compositions are given in Table 1. The photospheric composition is based on Anders \& Grevesse ( 1989), updated after Grevesse et al. (1990, 1991) for C and N; by Meyer (1989), Rubin et al. (1991), Widing, Feldman, \& Bhatia (1986), Feldman \& Widing ( 1990 ) for Ne; and by Grevesse \& Noels (1993) for Fe. The recent spectroscopic determinations of the photospheric $\mathrm{Fe}$ abundance agree with the meteoritic determinations (Grevesse \& Noels 1993 and references therein). For consistency, the coronal composition adopted here is the one derived from the gradual events observed by the same instrument as the impulsive events (ISEE 3; Cane et al. 1991) using the procedure of Meyer (1985a). The fact that all "coronal points" in Figures 8 and 13 lie right on the lines defined by the gradual events just reflects this approach. This composition is very similar to those of Meyer (1985a) and Breneman \& Stone (1985), after the latter have been readjusted for the new photospheric Fe abundance (Reames 1992; Meyer 1993a, b). The differences between coronal and photospheric abundances follow the welldescribed dependence on the first ionization potential (FIP) of the elements.

In each particular plot of abundance ratios, events were accepted provided they had a greater than $60 \%$ error on both considered element ratios. Correlations in abundance variations have been studied using usual weighted two-dimensional linear least-squares fits to the data. But errors on both ordinates and abscissae were considered. For each point, both its error and its distance to the regression line have been taken along the direction defined by the point itself and by the point of contact of its error ellipse with a parallel to the regression line (Wayman 1959; Fasano \& Vio 1988). Confidence intervals for the regression slopes have been estimated following Lampton, Margon, \& Bowyer (1976). We have also calculated the one-dimensional (logarithmic) average value of each abundance ratio taken independently.

We have also investigated the spread of the points, including the spread with respect to the regression line (two-dimensional) and the spread of each abundance ratio with respect to its own average value (one-dimensional) and associated $\chi^{2}$ for consistency with a constant value. Hereafter, all values of $\chi^{2}$ actually refer to values of reduced $\chi^{2}$. In some cases, the spread of the points is within statistical errors $\left(\chi^{2} \sim 1\right)$, and only a rough upper limit to the true "population" spread $\sigma_{\text {pop }}$ can be given. For others, $\chi^{2}$ is greater than 1 , and there exists a significant nonstatistical "population" spread

$$
\sigma_{\text {pop }}^{2}=\left(\chi^{2}-1\right) \sigma_{\text {stat }}^{2},
$$

where $\sigma_{\text {stat }}$ is the weighted mean statistical error of the observed points. But we want, as much as statistics permit, to get eventrather than count-weighted regression slopes and averages. Given $\sigma_{\mathrm{pop}}$, we therefore refit the data to redetermine regression slopes and mean abundance ratios, using weighting factors derived from $\sigma_{\text {pop }}$ in quadrature with the statistical errors of each point. This procedure adequately yields a unique weight for all events observed with errors small compared to $\sigma_{\text {pop }}$ and a statistical weighting of the events with larger errors. Throughout this paper, we give $95 \%(2 \sigma)$ confidence intervals for the regression slopes, and multiplicative spread factors $\sigma_{\mathrm{pop}}$ for individual abundance ratios including $95 \%$ of the points ( 2 $\sigma$ intervals) (see Table 3 ).

\section{RESULTS}

\subsection{General Properties of the ${ }^{3} \mathrm{He}$-rich Events}

The time distribution of the $228{ }^{3} \mathrm{He}$-rich events is shown in the upper panel of Figure 4. After 1983 the coverage of the

TABLE 1

PHOTOSPHERIC AND CORONAL ABUNDANCES ${ }^{\mathrm{a}}$

\begin{tabular}{|c|c|c|c|}
\hline \multirow{2}{*}{$\frac{\text { Element }}{\mathrm{H} \ldots \ldots \ldots}$} & \multirow{2}{*}{$\begin{array}{c}\text { Photosphere } \\
2820000(1.05)\end{array}$} & \multicolumn{2}{|c|}{ Corona } \\
\hline & & 668000 & $(1.10)$ \\
\hline $\mathrm{He} \ldots \ldots \ldots$ & $275000(1.08)$ & 31400 & $(1.05)$ \\
\hline C. & $1123(1.12)$ & 269 & $(1.10)$ \\
\hline $\mathrm{N}$ & $282(1.12)$ & 73 & $(1.07)$ \\
\hline O... & $2400(1.08)$ & 571 & $(1.07)$ \\
\hline Ne $\ldots \ldots \ldots$. & 387 (1.26) & 88 & $(1.10)$ \\
\hline $\mathrm{Mg} \ldots \ldots \ldots$ & $107(1.05)$ & 126 & $(1.05)$ \\
\hline $\mathrm{Si} \ldots \ldots \ldots$ & $100(1.05)$ & 100 & $(1.05)$ \\
\hline$S \ldots \ldots \ldots$ & $49(1.12)$ & 27.6 & $(1.07)$ \\
\hline $\mathrm{Fe} \ldots \ldots \ldots$ & $91(1.02)$ & 99 & $(1.07)$ \\
\hline
\end{tabular}

NoTE.-Errors in parentheses mean "within a factor of. ..."

${ }^{a}$ Normalized to $\mathrm{Si}$. 


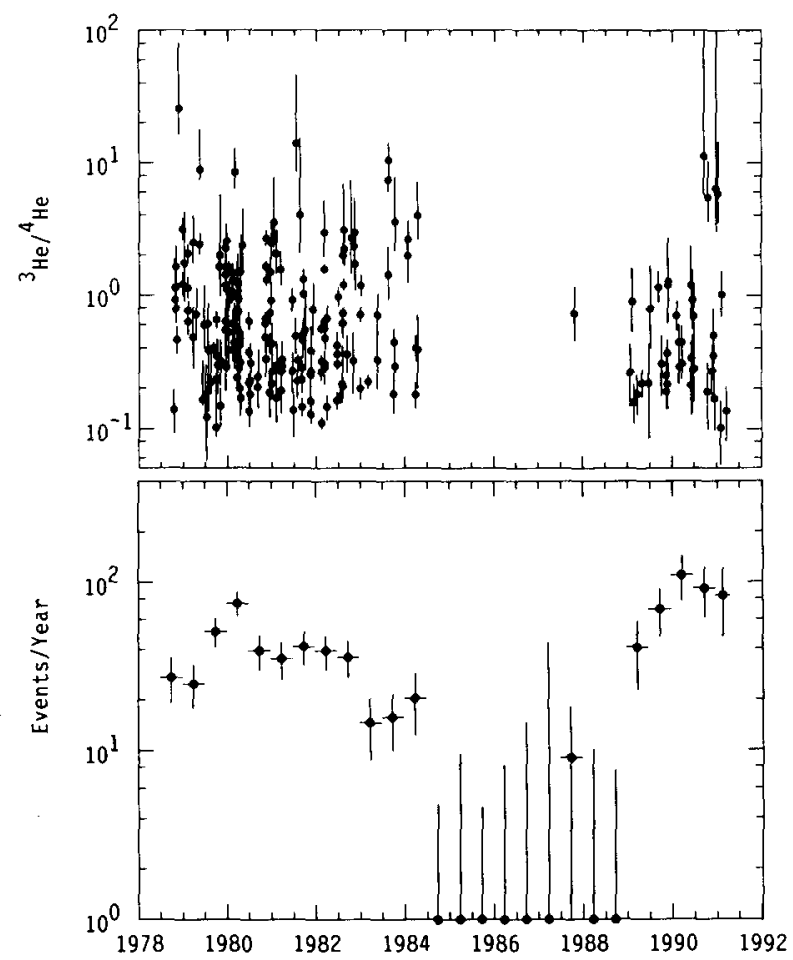

FIG. 4.-Time distribution of the individual ${ }^{3} \mathrm{He}$-rich events (upper panel) and the average rate of occurrence of the events corrected for poor coverage of the spacecraft (lower panel).

spacecraft by the Deep Space Network was only a few hours per day; therefore, we show in the lower panel of the figure the corrected event rate averaged over 6 month intervals. Although only upper limits are determined during solar minimum because of the poor coverage of the spacecraft, the solarcycle dependence of the event rate can be clearly seen in the figure. With $100 \%$ coverage of the spacecraft, we would have seen $\sim 1000{ }^{3} \mathrm{He}$-rich events during the study period, rather than 228 .

During solar maximum we observe $\sim 100$ events $\mathrm{yr}^{-1}$ at 1 $\mathrm{AU}$ (corrected for coverage). To compare with the rate of flare observations, however, we must correct for the fact that the particle events are only seen from a limited band of solar longitude that is magnetically connected with the spacecraft near 1 AU. Since this longitude band is $\sim 10^{\circ}-20^{\circ}$ (Reames, Kallenrode, \& Stone 1991a; Reames 1993), our event rate corresponds to $\sim 1000$ events $\mathrm{yr}^{-1}$, on the visible disk of the Sun. For comparison, the corresponding rates of hard X-ray bursts (Dennis et al. 1991), H $\alpha$ flares (Solar Geophysical Data [SGD]), and metric type III radio bursts (SGD) are $\sim 4000$, $\sim 10,000$, and $\sim 10,000$ events $\mathrm{yr}^{-1}$, respectively. Thus, at the present level of sensitivity, energetic ions are only seen from $\sim 10 \%$ of impulsive solar flares.

There are four abundance ratios that are used to distinguish impulsive and gradual events: ${ }^{3} \mathrm{He} /{ }^{4} \mathrm{He}, \mathrm{Fe} / \mathrm{C}($ or $\mathrm{Fe} / \mathrm{O}$ ), $\mathrm{H} /{ }^{4} \mathrm{He}$, and $e / p$. Within the class of impulsive events, however, event-to-event variations in these ratios are uncorrelated. Figure 5 shows the $4.4-6.4 \mathrm{MeV} \mathrm{amu}^{-1} \mathrm{H}$ intensity and $\mathrm{H} /{ }^{4} \mathrm{He}$ ratio versus ${ }^{3} \mathrm{He} /{ }^{4} \mathrm{He}$. At $\mathrm{l}-4 \mathrm{MeV} \mathrm{amu}{ }^{-1}$ the $\mathrm{H} /{ }^{4} \mathrm{He}$ ratio (not shown) is systematically lower, but the correlation with ${ }^{3} \mathrm{He} /{ }^{4} \mathrm{He}$ is equally poor. These observations do not seem to support theories (Fisk 1978; Riyopoulos 1991) where the generation of the waves that enhance ${ }^{3} \mathrm{He}$ increases with increasing ${ }^{4} \mathrm{He} / \mathrm{H}$ in the flare plasma.

The tendency toward decreasing ${ }^{3} \mathrm{He} /{ }^{4} \mathrm{He}$ with increasing proton intensity (Ramaty et al. 1980) is not well supported by the data in Figure 5, partly because events with low values of ${ }^{3} \mathrm{He} /{ }^{4} \mathrm{He}$ are not resolved by the VLET. In a later section we will discuss the decrease in ${ }^{3} \mathrm{He} /{ }^{4} \mathrm{He}$ in large events in terms of depletion of ${ }^{3} \mathrm{He}$ in the source volume.

Mason et al. (1986) first noted the lack of correlation between the enrichment of $\mathrm{Fe}$ and ${ }^{3} \mathrm{He} /{ }^{4} \mathrm{He}$. This is seen for the present data in Figure 6.

\section{2. ${ }^{4} \mathrm{He}$ and $\mathrm{C}$}

In Figure 7 we show ${ }^{4} \mathrm{He} / \mathrm{C}$ as a function of $\mathrm{Fe} / \mathrm{C}$ for ${ }^{3} \mathrm{He}-$ rich events. There is no evidence of a correlation with $\mathrm{Fe} / \mathrm{C}$ ( or with ${ }^{3} \mathrm{He} /{ }^{4} \mathrm{He}$, not shown). The mean value ${ }^{4} \mathrm{He} / \mathrm{C}$ is $99 \pm 16$ ( $2 \sigma$ error) for the events in Figure 7, while the coronal value from large gradual events is $117 \pm 14$. Thus $C$ is not significantly enhanced. The spread in the values of ${ }^{4} \mathrm{He} / \mathrm{C}$ exceeds that expected statistically, however, since the reduced $\chi^{2}$ is equal to 2.5; the corresponding value for $\mathrm{Fe} / \mathrm{C}$ is $\chi^{2}=3.8$. We

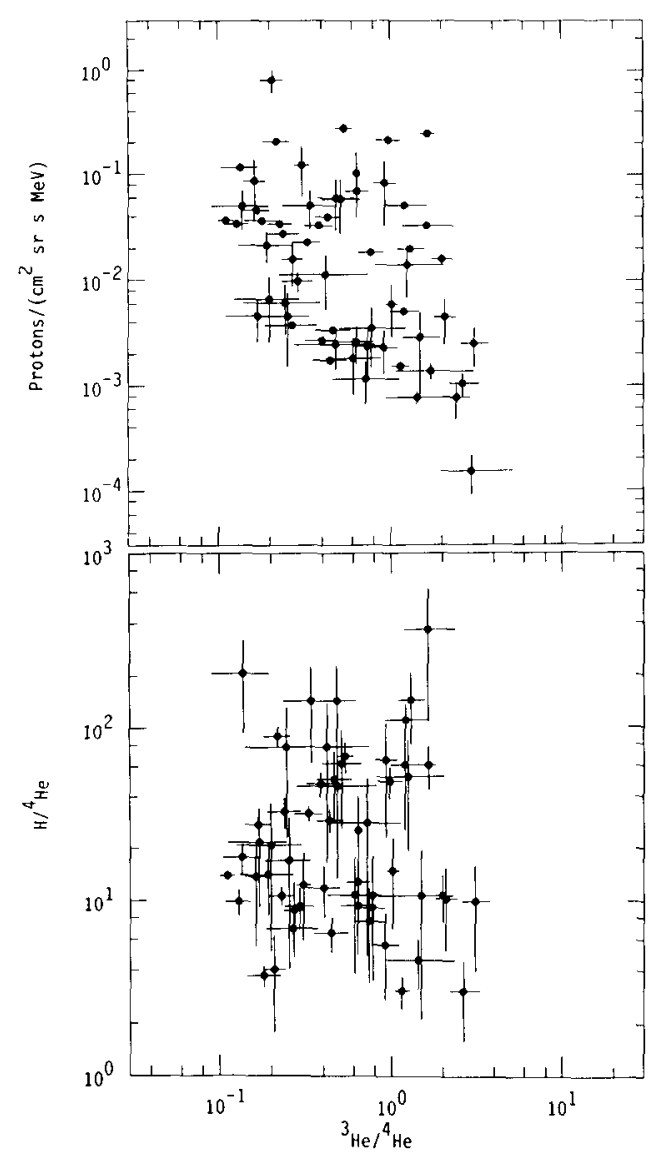

FIG. 5.-Intensity of 4.4-6.4 MeV protons (upper panel) and the 4.4$6.4 \mathrm{MeV} \mathrm{H} /{ }^{4} \mathrm{He}$ ratio (lower panel), shown as a function of the ${ }^{3} \mathrm{He} /{ }^{4} \mathrm{He}$ ratio. No strong correlations are seen. 


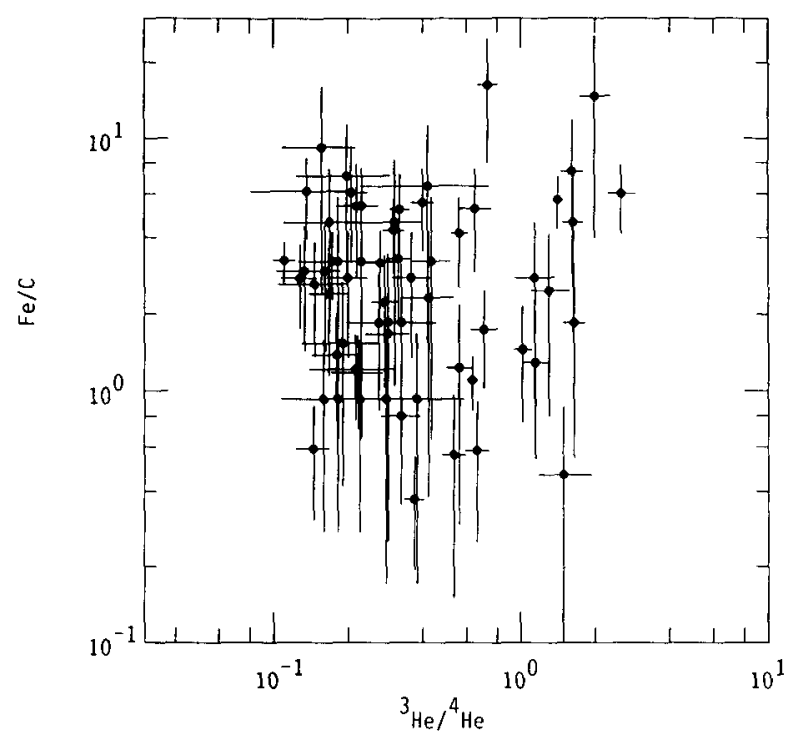

FIG. 6.-Fe/C $\left(2-3 \mathrm{MeV}\right.$ amu $\left.{ }^{-1}\right)$ is uncorrelated with ${ }^{3} \mathrm{He} /{ }^{4} \mathrm{He}$, as was previously observed by Mason et al. (1986).

will interpret lack of a $C$ enhancement as evidence that $C$ is fully ionized in the source plasma. Since fully stripped $\mathrm{C}$ has the same gyrofrequency as ${ }^{4} \mathrm{He}$, it could not be selectively enhanced by wave absorption. That being the case, the nonstatistical variations in ${ }^{4} \mathrm{He} / \mathrm{C}$ must exist in the underlying plasma prior to particle acceleration.

\subsection{The Element $/ \mathrm{C}$ versus $\mathrm{Fe} / \mathrm{C}$ Correlations}

Figure 8 shows the element/C versus $\mathrm{Fe} / \mathrm{C}$ ratios for the elements $\mathrm{N}, \mathrm{O}, \mathrm{Ne}, \mathrm{Mg}, \mathrm{Si}, \mathrm{S}$, for both gradual and impulsive events. The $\mathrm{Fe} / \mathrm{C}$ ratio is taken as the most sensitive indicator of the general enrichment of heavier elements relative to the lighter ones.

The gradual events are all observed with a very high statistical accuracy. They always form a well-defined line passing through the coronal point (which was actually determined on the basis of these same events), though with a finite spread. The slope of the correlation with $\mathrm{Fe} / \mathrm{C}$ increases with the atomic number, from almost zero for $\mathrm{N} / \mathrm{C}$ to $\sim 0.7$ for $\mathrm{S} / \mathrm{C}$. The abrupt increase of the slope between $\mathrm{Mg} / \mathrm{C}$ and $\mathrm{Si} / \mathrm{C}$ in the gradual events is striking. This abrupt increase fits well with the idea that gradual events result from the shock acceleration of plain coronal or solar wind material, whose composition is distorted only by smooth charge-to-mass $(Q / A)$ dependent biases, which result from the rigidity-dependent conditions for acceleration in each particular event. One then expects that abundance ratios of elements with similar $Q / A$ 's will remain quite constant, while those with widely different $Q / A$ 's will be subjected to large variations. The observed charge states in gradual events (Luhn et al. 1984, 1985), which agree roughly with those predicted for a $\sim 1.5-2 \mathrm{MK}$ plasma at equilibrium, indeed indicate that the $Q / A$ ratios remain fairly close to that for $\mathrm{C}$ for all elements up to $\mathrm{Mg}$, and start to decrease abruptly in the Si-S region (Meyer 1985a; Breneman \& Stone 1985; see Fig. 14 for a temperature of $1.5 \mathrm{MK}$ ).
The observations of the smaller impulsive, ${ }^{3} \mathrm{He}$-rich, events are of course affected by much larger statistical errors. Important trends can nevertheless be established. In impulsive events, $\mathrm{O} / \mathrm{C}$ and $\mathrm{N} / \mathrm{C}$ remain close to coronal values; they will be discussed in detail below. The $\mathrm{Ne} / \mathrm{C}, \mathrm{Mg} / \mathrm{C}, \mathrm{Si} / \mathrm{C}$, and $\mathrm{S} / \mathrm{C}$ ratios all vary over a wide range extending between approximately coronal and $\sim 7-10$ times coronal values, and are definitely correlated with $\mathrm{Fe} / \mathrm{C}$. The $\mathrm{Ne} / \mathrm{C}$ and $\mathrm{Mg} / \mathrm{C}$ plots are particularly instructive in showing two totally distinct slopes of the correlation with $\mathrm{Fe} / \mathrm{C}$ for gradual and for impulsive events. The slopes for the various correlations in Figure 8 are summarized in Table 2.

It may be noted that the best-fit slopes for $\mathrm{Ne} / \mathrm{C}, \mathrm{Mg} / \mathrm{C}$, $\mathrm{Si} / \mathrm{C}$, and $\mathrm{S} / \mathrm{C}$ versus $\mathrm{Fe} / \mathrm{C}$ are very closely equal for impulsive events. While the best regression lines for $\mathrm{Ne}$ and $\mathrm{S}$ pass through the coronal point, those for $\mathrm{Mg}$ and $\mathrm{Si}$ pass below. In the case of $\mathrm{Mg}$, the line is only marginally consistent with passing through the coronal point at the $2 \sigma$ level. If we force these regression lines to pass through the coronal point, their slopes become distinctly smaller than those for $\mathrm{Ne}$ and $\mathrm{S}$. This matter will be discussed more completely in $\S 3.6$.

For all elements from Ne upward, the clear correlations of element $/ \mathrm{C}$ with $\mathrm{Fe} / \mathrm{C}$ in impulsive events primarily describe the fact that heavier elements between $\mathrm{Ne}$ and $\mathrm{Fe}$ are all, globally, enhanced by comparable factors relative to $\mathrm{C}$ and ${ }^{4} \mathrm{He}$ (which are, indeed, not selectively accelerated in impulsive events at all). More precisely, it reflects the fact that, in Figure 8 , the spread on the abundances of these elements relative to $\mathrm{Fe}$ (element $/ \mathrm{Fe}$ ) is smaller than the spread on their abundances relative to C (element/C) ( see § 3.7, Fig. 13, Table 3). Therefore, the correlations reflect mainly this predominant spread on element/C, which is expressed in both coordinates. For Si and S this remark on the spreads becomes applicable to gradual events as well, and this may be the reason why the

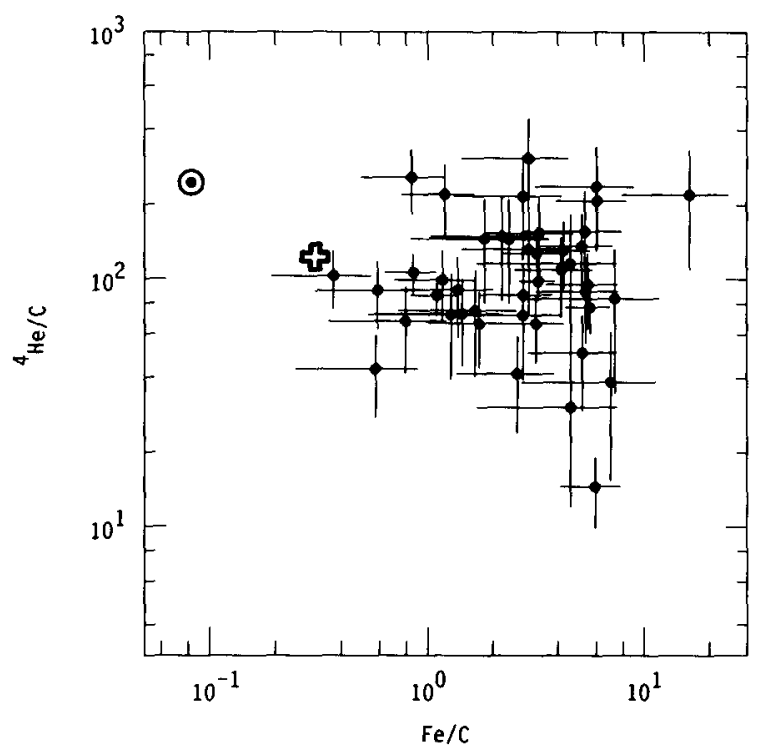

FIG. 7. $-{ }^{4} \mathrm{He} / \mathrm{C}\left(2-3 \mathrm{MeV}\right.$ amu $\left.{ }^{-1}\right)$ is uncorrelated with $\mathrm{Fe} / \mathrm{C}$ in ${ }^{3} \mathrm{He}$ rich events. The mean value of ${ }^{4} \mathrm{He} / \mathrm{C}$ is consistent with the coronal value (large plus sign), but the variance is 2.5 times larger than statistical, indicating possible variations in the abundances in the underlying flare plasma. 

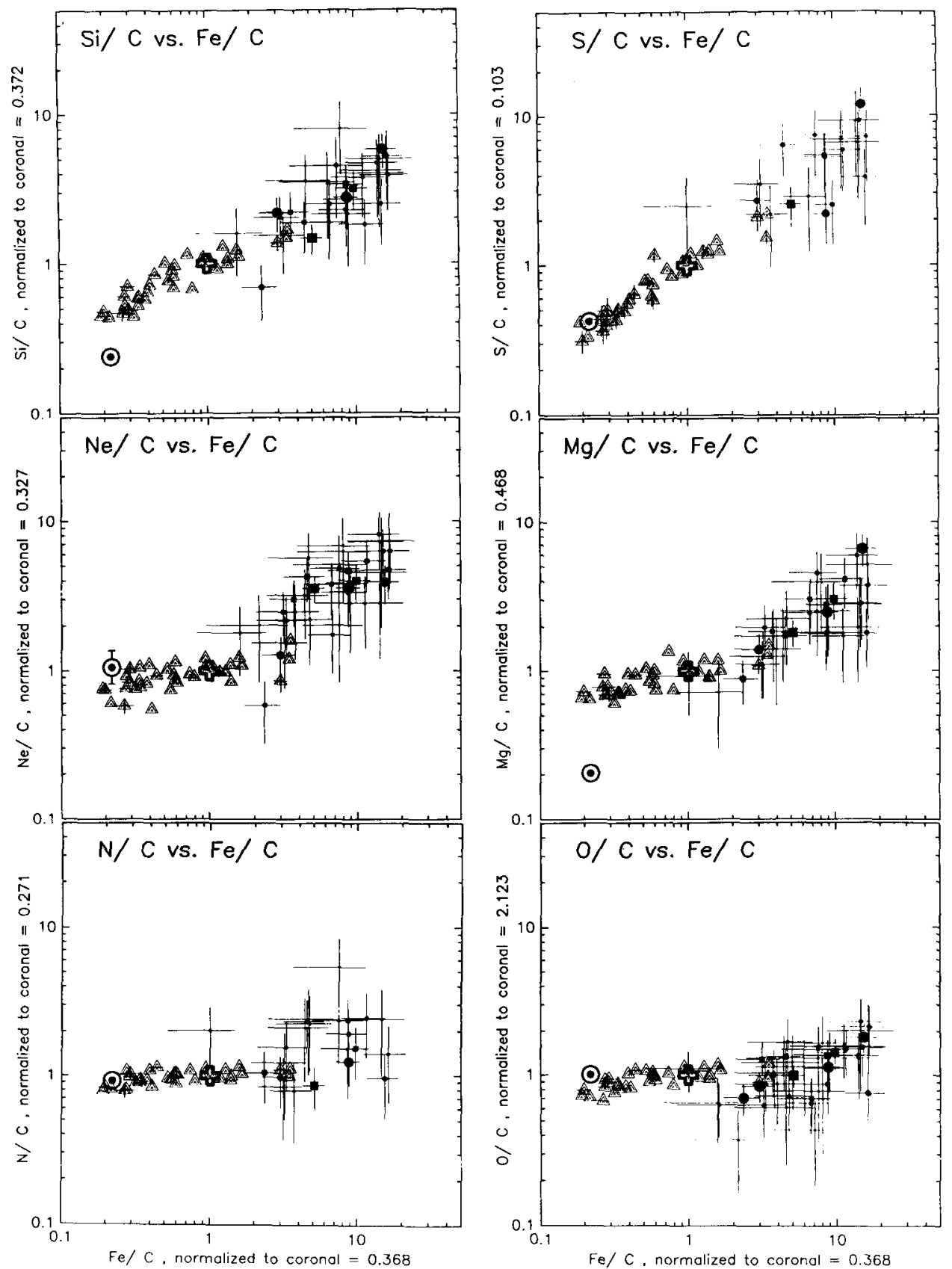

FIG. 8.-Correlation plots of the abundances of several elements as a function of the Fe abundance, all normalized to C. Impulsive events (filled symbols) are compared with large proton events (triangles) in each panel. The size of the symbols varies inversely with the statistical errors in order to emphasize the most accurate events. Photospheric and coronal abundances are shown by a large circle and a large plus sign, respectively.

regression slopes then become similar for both families of events.

So the plots in Figure 8 give a good description of the enhancement of heavier elements relative to $C$, which is presumably not selectively accelerated. They are, however, not appropriate for comparing abundance enhancements of the various selectively accelerated elements and, hence, for placing constraints on the selective acceleration mechanisms at work in impulsive events. Therefore, we now discuss more specific element ratios.

\subsection{Do the Particles Accelerated in Impulsive Events Originate in Photospheric- or in Coronal-Type Material?}

For all elements, the range of ratios to C observed in impulsive events starts near the coronal, not the photospheric, point (Fig. 8). For most elements, the regression line with $\mathrm{Fe} / \mathrm{C}$ passes near both the coronal and the photospheric point; but in the case of the $\mathrm{Ne} / \mathrm{C}$ versus $\mathrm{Fe} / \mathrm{C}$ plot (high FIP/high FIP versus low FIP/ high FIP), the regression line passes unambiguously near the coronal, not the photospheric, point. Further, it 
TABLE 2

ElEMENT/C VERSUS Fe/C REgResSIONS FOR GRADUAL AND IMPULSIVE EvENTS

\begin{tabular}{lccccc}
\hline & \multicolumn{2}{c}{$\begin{array}{c}\text { MEAN ENHANCEMENT } \\
\text { RELATIVE TO CORONA }\end{array}$} & & \multicolumn{2}{c}{$\begin{array}{c}\text { SLOPE OF REGRESSION } \\
\text { VERSUS Fe/C }\end{array}$} \\
\cline { 2 - 3 } $\begin{array}{c}\text { ABUNDANCE } \\
\text { RATIO }\end{array}$ & Gradual $^{\mathrm{a}}$ & Impulsive & & Gradual & Impulsive \\
\hline $\mathrm{N} / \mathrm{C} \ldots \ldots \ldots \ldots$ & $0.97 \pm 0.04$ & $1.52 \pm 0.34$ & & $+0.08 \pm 0.05$ & $+0.15_{-0.43}^{+0.51}$ \\
$\mathrm{O} / \mathrm{C} \ldots \ldots \ldots \ldots$ & $0.93 \pm 0.04$ & $1.10 \pm 0.12$ & & $+0.13 \pm 0.06$ & $+0.37_{-0.22}^{+0.28}$ \\
$\mathrm{Ne} / \mathrm{C} \ldots \ldots \ldots$ & $0.92 \pm 0.06$ & $3.51 \pm 0.50$ & & $+0.19 \pm 0.09$ & $+0.73_{-0.34}^{+0.46}$ \\
$\mathrm{Mg} / \mathrm{C} \ldots \ldots \ldots$ & $0.88 \pm 0.06$ & $2.35 \pm 0.32$ & & $+0.24 \pm 0.09$ & $+0.74_{-0.30}^{+0.38}$ \\
$\mathrm{Si} / \mathrm{C} \ldots \ldots \ldots \ldots$ & $0.79 \pm 0.05$ & $2.76 \pm 0.38$ & & $+0.45 \pm 0.09$ & $+0.74_{-0.34}^{+0.46}$ \\
$\mathrm{~S} / \mathrm{C} \ldots \ldots \ldots$ & $0.79 \pm 0.04$ & $4.69 \pm 1.04$ & & $+0.62 \pm 0.08$ & $+0.68_{-0.45}^{+0.60}$ \\
$\mathrm{Fe} / \mathrm{C} \ldots \ldots \ldots$ & $0.68 \pm 0.03$ & $6.67 \pm 0.80$ & & +1.00 & +1.00 \\
\hline
\end{tabular}

NOTE.-All errors are given at the $95 \%$ confidence $(2 \sigma)$ level.

"Enhancements are of order unity for gradual events because "coronal" abundances are derived from them; they decrease with $Z$ because there are more $\mathrm{Fe}$-poor than $\mathrm{Fe}$-rich events.

is striking to see in Figures 8, 10, and especially 13 how $\mathrm{Ne}, \mathrm{Mg}$ and $\mathrm{Si}$ behave alike when normalized to the corona and differently when normalized to the photosphere. Figures 10 and 11 also show that the $\mathrm{Ne} / \mathrm{MgSi}$ ratios observed in impulsive events are much closer to the coronal than to the photospheric ratio.

Thus, the composition observations strongly suggest that the particles accelerated in impulsive (as well as gradual!) events originated in a gas with coronal, not photospheric, composition.

\subsection{The $\mathrm{O} / \mathrm{C}$ and $\mathrm{N} / \mathrm{C}$ Ratios}

The $\mathrm{O} / \mathrm{C}$ versus $\mathrm{Fe} / \mathrm{C}$ cross-plot in Figure 8 obviously displays a positive correlation between $\mathrm{O} / \mathrm{C}$ and $\mathrm{Fe} / \mathrm{C}$ (slope = $0.37_{-0.22}^{+0.28}$ ). Now, irrespective of the $\mathrm{Fe} / \mathrm{C}$ values, the spread on the observed $\mathrm{O} / \mathrm{C}$ ratios is symmetrical around the coronal value and amounts to a factor of 2.0 only. Actually, all the observed $\mathrm{O} / \mathrm{C}$ ratios are consistent with the coronal value ( average $=1.10 \pm 0.11$ times coronal; $\chi^{2}=0.94$ for constant $\mathrm{O} / \mathrm{C}$ ). So the observed spread is predominantly statistical, and the nonstatistical population spread on the true $\mathrm{O} / \mathrm{C}$ ratios in impulsive events is probably smaller than a factor of $\sim 1.42$ around the coronal value (see Table 3 ).

These remarks, while not strictly refuting the hypothesis of a true correlation of $\mathrm{O} / \mathrm{C}$ with $\mathrm{Fe}$ enrichment, do cast some doubt on its reality and lead us to examine the problem more closely. (Note that none of these remarks would apply to any of the heavier element plots. The $\mathrm{O} / \mathrm{C}$ plot is also the only one in Figure 8 in which the regression line for impulsive events does not pass through the coronal point, at the $95 \%$ confidence level).

We have a particular problem in analyzing the $\mathrm{O} / \mathrm{C}$ versus $\mathrm{Fe} / \mathrm{C}$ plot. When plotting, one against the other, two ratios in which the same element appears in both coordinates, the statistical fluctuations on this repeated element, reflected identically on both coordinates, tend to introduce a "pseudocorrelation" along the first or the second diagonal, according to whether the repeated element lies in the same position or in opposite positions in both ratios. The measurement errors on the quantities plotted in abscissae and in ordinates are not entirely statistically independent. This effect tends to increase the observed slope as compared with what it would be in the absence of statistical fluctuations in the first case, and to decrease it in the second case. When the total amplitude of the true variations is large as compared with these statistical fluctuations, or when the dominant error is not that on the repeated element, this effect is not very important. This is the case in most of the plots in Figure 8.

But in the case of $\mathrm{O} / \mathrm{C}$ versus $\mathrm{Fe} / \mathrm{C}$ neither of these two conditions is met. Indeed, the $\chi^{2}$ value for the points relative to the regression line with slope $0.37_{-0.22}^{+0.28}$ is only 0.55 , a very anomalously low value that indicates that the quantities plotted in abscissae and in ordinates share correlated statistical fluctuations. Thus, the regression slope can be significantly enhanced, relative to what it would be if the measurement errors on the repeated element, $\mathrm{C}$, were negligible.

To investigate further the reality of a correlation of $\mathrm{O} / \mathrm{C}$ with $\mathrm{Fe}$ enrichment, we compare in Figure 9 the plots of the $\mathrm{O} / \mathrm{C}$ ratio versus $\mathrm{Fe} / \mathrm{C}, \mathrm{Fe} / \mathrm{O}, \mathrm{Fe} / \mathrm{CNO}$, and $\mathrm{Fe} / \mathrm{N}$. In the plot versus $\mathrm{Fe} / \mathrm{O}$, the statistical fluctuations on repeated $\mathrm{O}$ tend to disperse the points along the second diagonal, thus decreasing the observed slope; the observed slope of $0.12_{-0.28}^{+0.30}$, perfectly consistent with zero, should therefore be considered as a lower limit. In the plot versus $\mathrm{Fe} / \mathrm{CNO}$, it is expected that the trends of the statistical fluctuations on $\mathrm{C}$ and on $\mathrm{O}$ to disperse the points along the first and the second diagonal should more or less cancel. In the plot versus $\mathrm{Fe} / \mathrm{N}$, the abscissae are affected by statistical fluctuations which are very large but are independent of those affecting the ordinates. Both of these plots yield very similar regression slopes of $\sim 0.24_{-0.25}^{+0.32}$. These slopes are consistent with zero at the $6 \%$ significance level. Also, both regression lines are consistent with passing through the coronal point.

It is also noteworthy that we do not find in our data any evidence for the existence of a class of "C-poor" or "O-rich" events, corresponding to a significant one-sided tail of events with high $\mathrm{O} / \mathrm{C}$ ratios (Fig. 9). The existence of such a tail, with enhancements of $\mathrm{O} / \mathrm{C}$ by factors up to $\sim 5$, has been reported, 

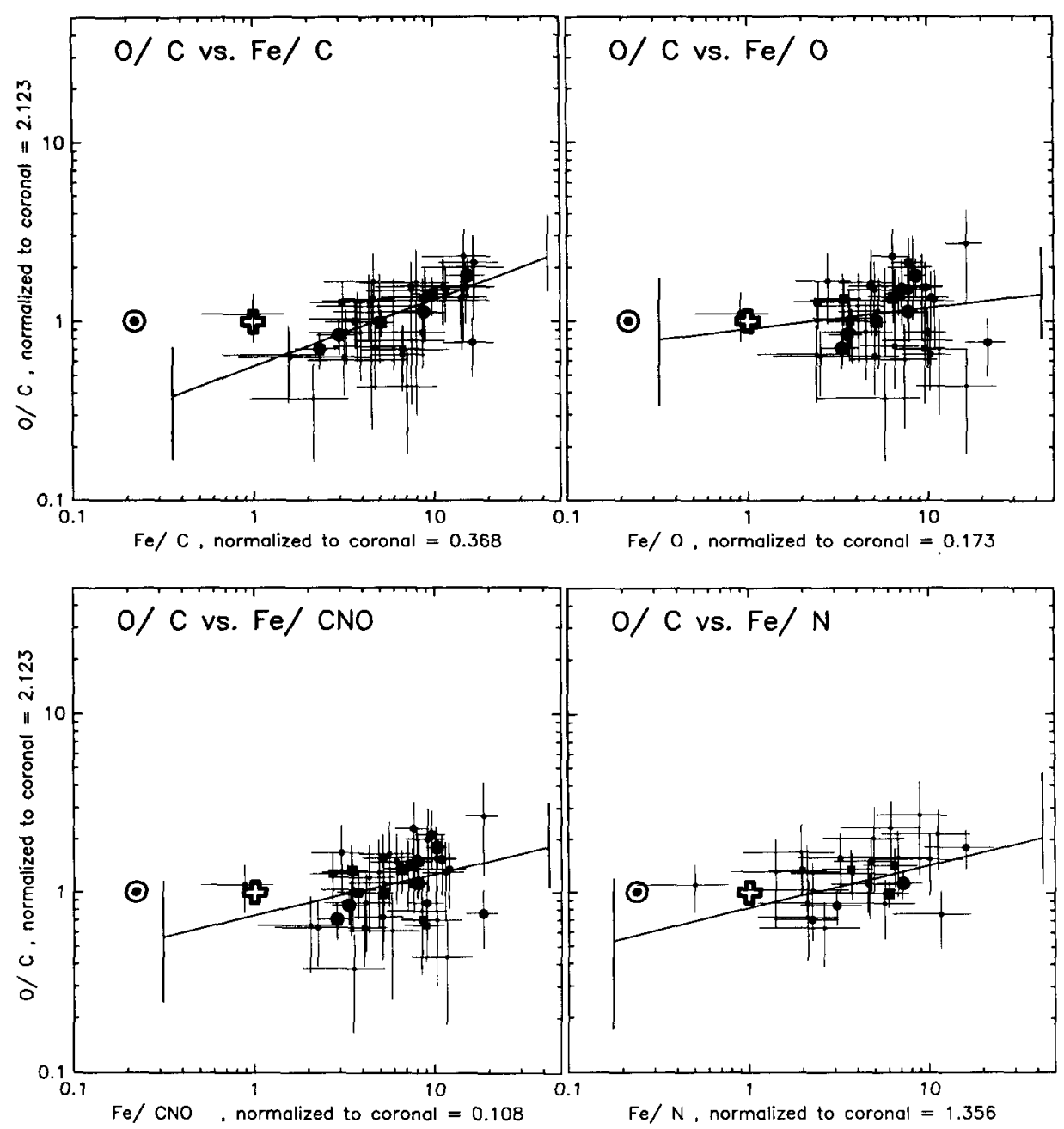

Fig. 9.-Correlation plots of $\mathrm{O} / \mathrm{C}$ vs. $\mathrm{Fe} / \mathrm{C}, \mathrm{Fe} / \mathrm{O}, \mathrm{Fe} / \mathrm{N}$, and $\mathrm{Fe} / \mathrm{CNO}$ with the least-squares fit lines show that the effect of the repeated element, $\mathrm{C}$, in the denominator explains part of the correlation in the first panel.

based on measurements by the University of Maryland / MaxPlanck-Institut (UMd/MPI) instruments on IMP 8 (Mason, Gloeckler, \& Hovestadt 1979; Mason et al. 1980) and ISEE 3 (Mason et al. 1986), and by the Goddard instrument on ISEE 3 (Reames \& von Rosenvinge 1981). These Goddard ISEE 3 data are but a small subset of the present data. The IMP 8 UMd/MPI data also cover only three "C-poor" events. The ISEE 3 UMd/MPI data represent a much more substantial set of data, covering the two energy ranges $1.0-1.8$ and 1.8-3.4 $\mathrm{MeV} \mathrm{amu}{ }^{-1}$; clear evidence for a tail of "C-poor" events was found in the lower energy range. We have compared the $\mathrm{O} / \mathrm{C}$ ratios observed by the UMd/MPI and by the Goddard instruments on board the same ISEE 3 spacecraft, at the same time periods, and in nearby energy ranges (1.0-1.8 and 1.9-2.8 $\mathrm{MeV} \mathrm{amu}{ }^{-1}$ ). The one-sided tail of events with high $\mathrm{O} / \mathrm{C} \mathrm{ra-}$ tios is not found in the Goddard data (Fig. 9). This difference is not understood.

The data on N/C have a much poorer statistical accuracy (Fig. 8). They are less affected by the "pseudocorrelation" problem because the statistical errors on $\mathrm{N}$ are much larger than those on $\mathrm{C}$. The regression slopes versus $\mathrm{Fe} / \mathrm{C}$ and $\mathrm{Fe} /$ $\mathrm{CNO}$, while plagued with large errors, are perfectly consistent with zero: $+0.15_{-0.43}^{+0.51}$ and $-0.01 \pm 0.47$. But, contrary to $\mathrm{O} / \mathrm{C}$, $\mathrm{N} / \mathrm{C}$ seems on the average slightly enhanced relative to coronal (by a factor of $1.52 \pm 0.34$ ), though much less so than all elements from $\mathrm{Ne}$ upward. In view of the instrument charge resolution, we are confident that this observed enhancement is not due to spillover from neighboring $\mathrm{C}$ and $\mathrm{O}$ peaks.

In brief, all observed $\mathrm{O} / \mathrm{C}$ ratios are consistent with a single value, equal to the coronal value. However, our set of data points toward a slight correlation of $\mathrm{O} / \mathrm{C}$ with $\mathrm{Fe}$ enrichment in impulsive events ( slope $\sim 0.24$ ); it is consistent with a zero regression slope at the $6 \%$ confidence level only. N/C, much less accurately measured, seems on the average slightly higher than coronal ( $\mathrm{a}$ factor of $\sim 1.50$ ) but shows no indication of a correlation with $\mathrm{Fe}$ enrichment. More data are needed to check the reality of the high average $\mathrm{N} / \mathrm{O}$, and of the $\mathrm{O} / \mathrm{C}$ correlation with $\mathrm{Fe}$ enrichment. In any case, both the deviations of the average $\mathrm{O} / \mathrm{C}$ and $\mathrm{N} / \mathrm{C}$ ratios from their coronal values, and the slopes of their regressions versus $\mathrm{Fe} / \mathrm{C}$ or $\mathrm{Fe} /$ $\mathrm{CNO}$, are much smaller than those for all elements from $\mathrm{Ne}$ upward (Fig. 8; Tables 2 and 3).

There is a practical consequence to the limited character of the variations of $\mathrm{O} / \mathrm{C}$ and $\mathrm{N} / \mathrm{C}$ : although $\mathrm{Fe} / \mathrm{C}$ is, in principle, 


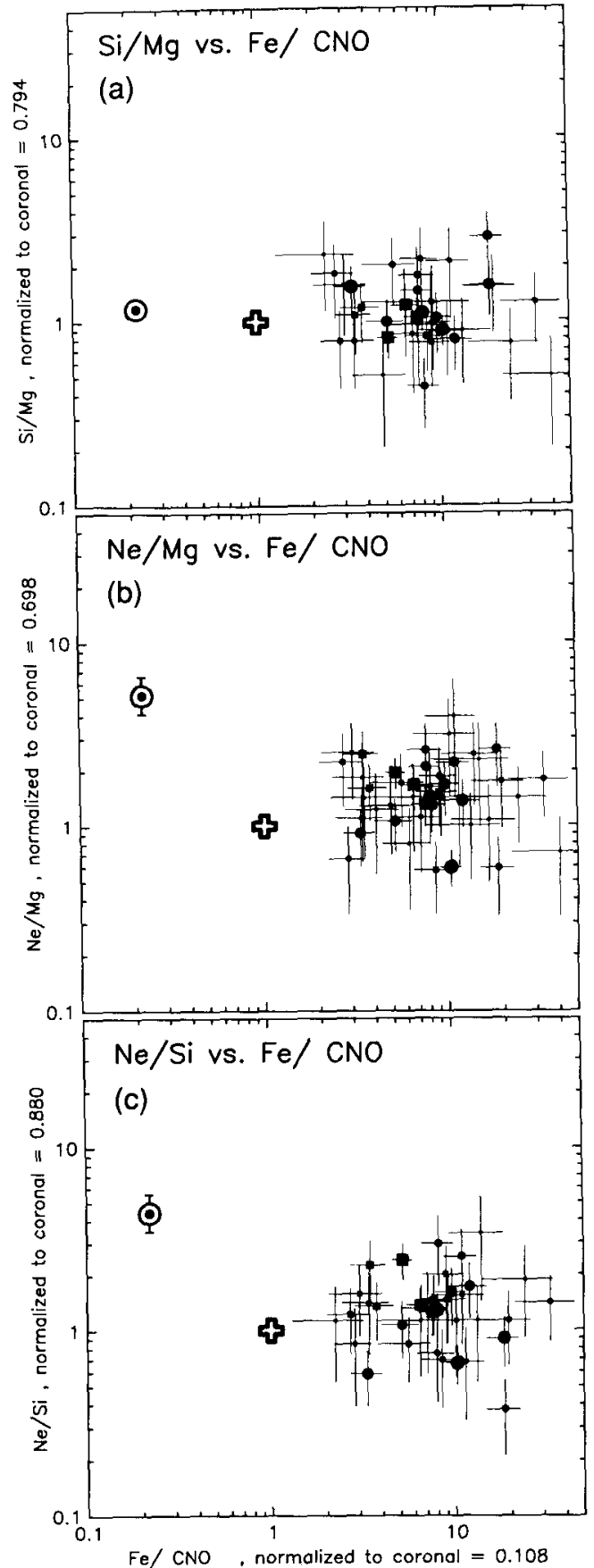

Fig. 10.-In impulsive events, the ratios of the elements $\mathrm{Ne}, \mathrm{Mg}$, and $\mathrm{Si}$ are independent of $\mathrm{Fe} / \mathrm{CNO}$. The $\mathrm{Si} / \mathrm{Mg}$ ratio lies close to the coronal value, while $\mathrm{Ne} / \mathrm{Mg}$ and $\mathrm{Ne} / \mathrm{Si}$ are elevated.

a better indicator of the amplitude of the selective enrichments in impulsive events, we do not lose much in sensitivity by using $\mathrm{Fe} / \mathrm{CNO}$ as an indicator instead. But we then gain a lot on the available statistics. We will therefore plot many ratios as a function of $\mathrm{Fe} / \mathrm{CNO}$.

\subsection{The $\mathrm{Ne} / \mathrm{Mg} / \mathrm{Si} / \mathrm{S}$ Ratios}

The abundance ratios of elements within the $\mathrm{Ne}, \mathrm{Mg}, \mathrm{Si}, \mathrm{S}$ group are extremely instructive. Figure 10 shows the $\mathrm{Si} / \mathrm{Mg}$,
$\mathrm{Ne} / \mathrm{Mg}$, and $\mathrm{Ne} / \mathrm{Si}$ ratios versus $\mathrm{Fe} / \mathrm{CNO}$. Its significance in indicating a coronal-type composition of the initial gas was discussed in $\S 3.4$. Further, it is striking that these three ratios seem completely independent of the Fe enrichment (see regression slopes in Table 3).

$\mathrm{The} \mathrm{Si} / \mathrm{Mg}$ ratio is, in addition, centered essentially on the coronal value (average $=1.11 \pm 0.14$ times coronal; Table 3 ). And there is even no evidence for any nonstatistical fluctuation of the true $\mathrm{Si} / \mathrm{Mg}$ ratio around the coronal value $\left(\chi^{2}=\right.$ 0.91 for a constant $\mathrm{Si} / \mathrm{Mg}$; upper limit to the $95 \%$ spread is a factor of $\sim 1.42$; Table 3). So $\mathrm{Mg}$ and $\mathrm{Si}$ seem to behave exactly alike in impulsive events. This allows us to plot other ratios over the sum $\mathrm{MgSi}$, thus improving our statistical accuracy.

Figure 11 thus shows the $\mathrm{Ne} / \mathrm{MgSi}$ and $\mathrm{S} / \mathrm{MgSi}$ ratios versus $\mathrm{Fe} / \mathrm{CNO}$. Both ratios seem independent of Fe/CNO (Table 3 ). But, in contrast to $\mathrm{Si} / \mathrm{Mg}$, both ratios are on the average close to, but significantly different from, coronal: the average $\mathrm{Ne} / \mathrm{MgSi}$ and $\mathrm{S} / \mathrm{MgSi}$ ratios are $1.46 \pm 0.18$ and $1.81 \pm 0.32$ times coronal, at the $2 \sigma$ level (Table 3 ). This leaves $\mathrm{Ne} / \mathrm{MgSi}$ much closer to the coronal than to the photospheric value, which is $\sim 4.80$ times higher. But the (less accurately ob-
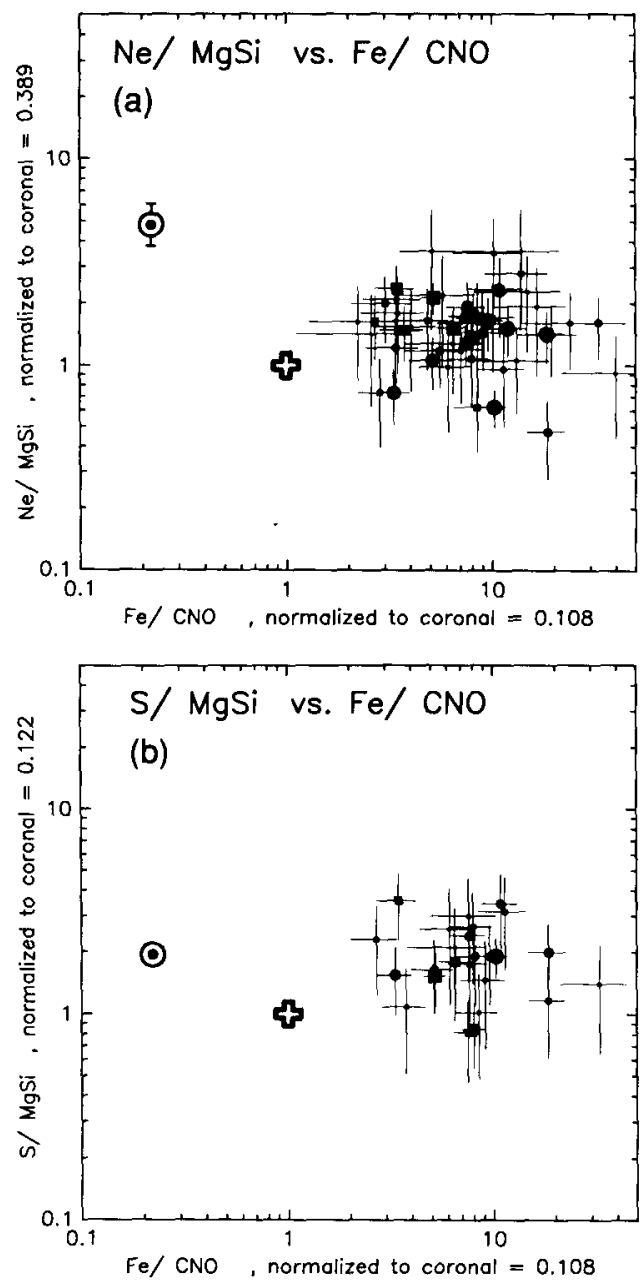

FIG. 11.-Ratios of $\mathrm{Ne} / \mathrm{MgSi}$ and $\mathrm{S} / \mathrm{MgSi}$ are independent of $\mathrm{Fe} /$ CNO but are enhanced relative to coronal abundances. 
TABLE 3

Statistical Properties of Key Abundance Ratios for Impulsive Events

\begin{tabular}{|c|c|c|c|c|c|c|c|}
\hline $\begin{array}{l}\text { ABUNDANCE } \\
\text { RATIO }\end{array}$ & \multicolumn{4}{|c|}{ ASSUMING UNIQUE RATIO } & \multicolumn{3}{|c|}{ ASSUMING LINEAR REGRESSION } \\
\hline $\begin{array}{l}\mathrm{O} / \mathrm{C} \ldots \ldots \ldots \ldots \ldots \ldots \\
\mathrm{N} / \mathrm{C} \ldots \ldots \ldots \ldots \ldots \ldots\end{array}$ & $\begin{array}{l}1.11 \pm 0.11 \\
1.52 \pm 0.34\end{array}$ & $\begin{array}{l}0.97 \\
0.84\end{array}$ & $\begin{array}{l}0.539 \\
0.674\end{array}$ & $\begin{array}{l}(<1.42) \\
(<1.56)\end{array}$ & $\begin{array}{l}\mathrm{Fe} / \mathrm{CNO} \\
\mathrm{Fe} / \mathrm{CNO}\end{array}$ & $\begin{array}{l}+0.24 \pm 0.25 \\
+0.01 \pm 0.47\end{array}$ & $\begin{array}{l}0.064 \\
0.997\end{array}$ \\
\hline $\begin{array}{l}\mathrm{Si} / \mathrm{Mg} \ldots \ldots \ldots \ldots \ldots \\
\mathrm{Ne} / \mathrm{Mg} \ldots \ldots \ldots \ldots \ldots \\
\mathrm{Ne} / \mathrm{Si} \ldots \ldots \ldots \ldots \ldots \\
\mathrm{Ne} / \mathrm{MgSi} \ldots \ldots \ldots \ldots \\
\mathrm{S} / \mathrm{MgSi} \ldots \ldots \ldots \ldots \ldots\end{array}$ & $\begin{array}{l}1.11 \pm 0.14 \\
1.45 \pm 0.20 \\
1.28 \pm 0.20 \\
1.46 \pm 0.18 \\
1.81 \pm 0.32\end{array}$ & $\begin{array}{l}0.91 \\
1.19 \\
1.32 \\
1.25 \\
0.83\end{array}$ & $\begin{array}{l}0.627 \\
0.178 \\
0.090 \\
0.105 \\
0.699\end{array}$ & $\begin{array}{c}(<1.47) \\
1.42 \\
1.54 \\
1.42 \\
(<1.47)\end{array}$ & $\begin{array}{l}\mathrm{Fe} / \mathrm{CNO} \\
\mathrm{Fe} / \mathrm{CNO} \\
\mathrm{Fe} / \mathrm{CNO} \\
\mathrm{Fe} / \mathrm{CNO} \\
\mathrm{Fe} / \mathrm{CNO}\end{array}$ & $\begin{array}{l}-0.03 \pm 0.30 \\
-0.07 \pm 0.34 \\
-0.07 \pm 0.39 \\
-0.06 \pm 0.29 \\
-0.06 \pm 0.45\end{array}$ & $\begin{array}{l}0.967 \\
0.884 \\
0.894 \\
0.879 \\
0.944\end{array}$ \\
\hline $\begin{array}{l}\mathrm{Fe} / \mathrm{Ne} \ldots \ldots \ldots \ldots \\
\mathrm{Fe} / \mathrm{MgSi} \ldots \ldots \ldots \ldots \\
\mathrm{Fe} / \mathrm{NeMgSi} \ldots \ldots \ldots\end{array}$ & $\begin{array}{l}2.10 \pm 0.24 \\
3.04 \pm 0.30 \\
2.81 \pm 0.22\end{array}$ & $\begin{array}{l}1.53 \\
1.43 \\
1.51\end{array}$ & $\begin{array}{l}0.009 \\
0.011 \\
0.003\end{array}$ & $\begin{array}{l}1.61 \\
1.49 \\
1.49\end{array}$ & $\begin{array}{l}\mathrm{Ne} / \mathrm{CNO} \\
\mathrm{MgSi} / \mathrm{CNO} \\
\mathrm{NeMgSi} / \mathrm{CNO}\end{array}$ & $\begin{array}{l}-0.69 \pm 0.57 \\
-0.11 \pm 0.34 \\
+0.02 \pm 0.31\end{array}$ & $\begin{array}{l}0.005 \\
0.656 \\
0.992\end{array}$ \\
\hline
\end{tabular}

NoTE.-All errors and intervals are given at the $95 \%$ confidence $(2 \sigma)$ level.

${ }^{a}$ Logarithmic averages.

${ }^{b}$ Probability of obtaining a $\chi^{2}$ at least as large as the observed $\chi^{2}$, if the true ratio is indeed constant.

'Multiplicative spread factors, on either side of the mean value, including $95 \%$ of the true points. When $\chi^{2} \leqslant 1$, we give a rough upper limit based on the assumption that less than $25 \%$ of the observed variance could originate in a true population spread.

served) S/MgSi ratio resembles more the photospheric ratio, which is, however, only $\sim 1.94$ times higher than coronal. In addition, the $\mathrm{Ne} / \mathrm{MgSi}$ plot shows some evidence for a nonstatistical spread of the true ratio, on the order of a factor of $\sim 1.42\left(\chi^{2}=1.25\right.$ for a constant $\mathrm{Ne} / \mathrm{MgSi}$; Table 3$)$.

The roughly similar behaviors of $\mathrm{Ne}$ and $\mathrm{MgSi}$ relative to coronal in impulsive events allows us to treat them as a single group of elements below, so as to increase the statistical significance of our data.

Figure 12 is a plot of $\mathrm{Si} / \mathrm{Mg}$ versus $\mathrm{Ne} / \mathrm{Mg}$ in impulsive events showing the proximity of these ratios to the coronal values. Note that there is no evidence of anticorrelation in the figure. We will argue in $\$ 4.3$ that this is evidence of an absence of large temperature fluctuations between events. A temperature increase could suppress $\mathrm{Ne}$ and enhance $\mathrm{Si}$ relative to $\mathrm{Mg}$, for example, causing an anticorrelation.

\subsection{Relative Abundances of Elements between $\mathrm{Ne}$ and $\mathrm{Fe}$ and Enhancements with Respect to CNO}

We now address a key question: what relationship exists between the abundance enhancements of heavier elements from $\mathrm{Ne}$ upward relative to $\mathrm{CNO}$ and the relative abundances among these heavier elements?

Figure 13 shows the cross-plots for $\mathrm{Fe} / \mathrm{Ne}$ versus $\mathrm{Ne} / \mathrm{CNO}$, $\mathrm{Fe} / \mathrm{MgSi}$ versus $\mathrm{MgSi} / \mathrm{CNO}$, and $\mathrm{Fe} / \mathrm{NeMgSi}$ versus $\mathrm{NeMgSi}$ / $\mathrm{CNO}$, which are relevant to this question. The first two plots show particularly conspicuously that the impulsive event compositions strongly suggest a coronal, not photospheric, composition for the parent gas. Indeed, high-FIP Ne and low-FIP $\mathrm{MgSi}$ behave roughly alike relative to the coronal point, and not at all so relative to the photospheric point (see $\$ 3.4$ ).
Based on these similar behaviors, we have summed $\mathrm{Ne}$ and $\mathrm{MgSi}$ in the third plot, which we now discuss more particularly. For gradual events, one can recognize the well-known behavior: a smooth correlation, with a small variation of $\mathrm{NeMgSi} / \mathrm{CNO}$ being associated with a large variation of $\mathrm{Fe} /$ $\mathrm{NeMgSi}$.

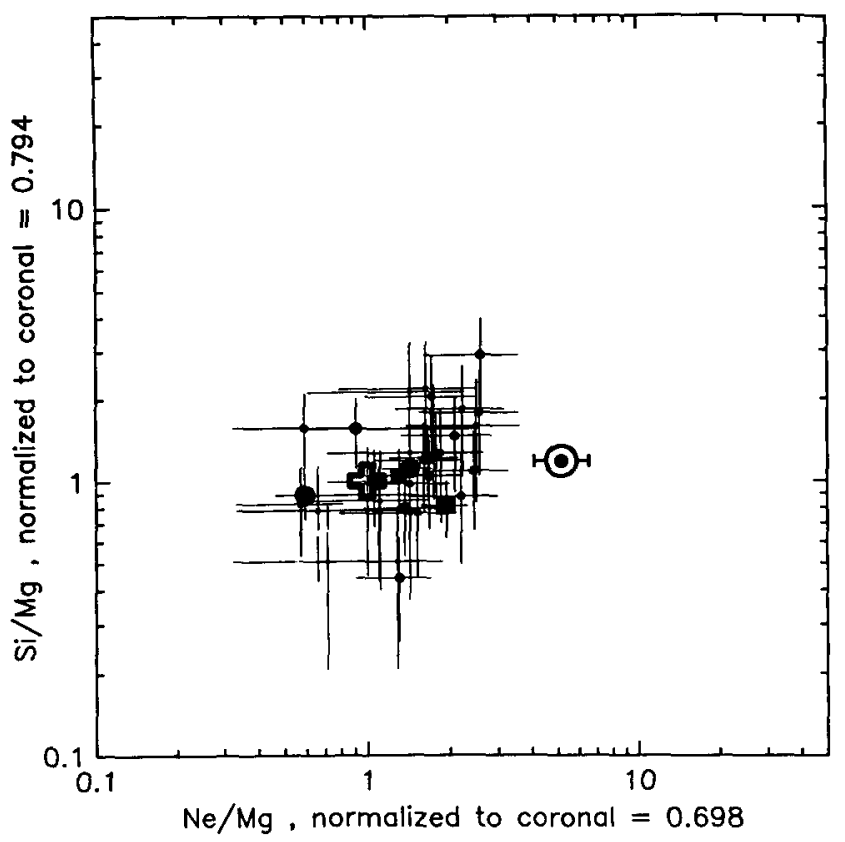

FIG. 12,- $\mathrm{Ne} / \mathrm{Mg}$ is not anticorrelated with $\mathrm{Si} / \mathrm{Mg}$, and both lie near the coronal abundance. 

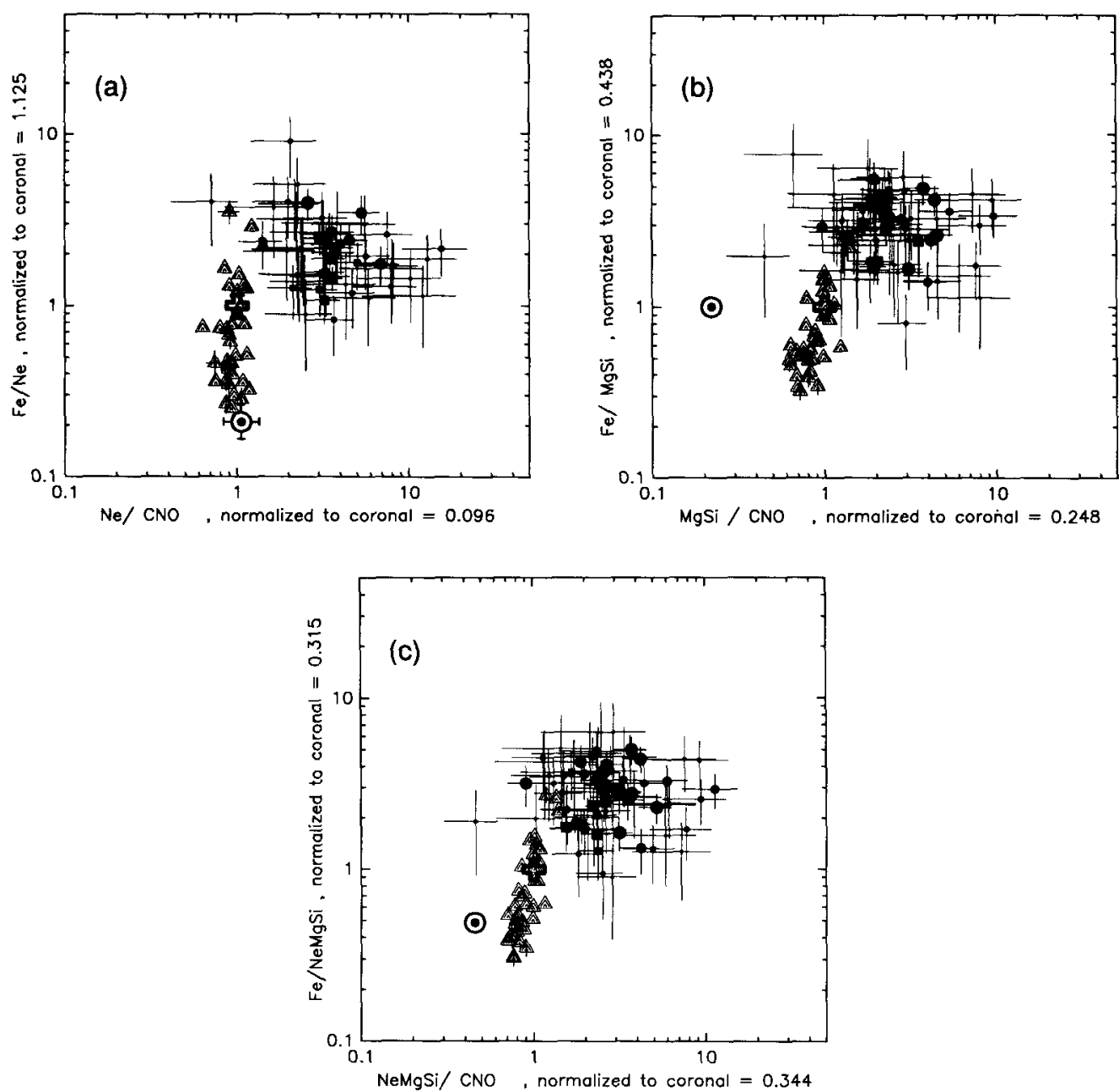

FiG. 13. - Comparison of the enhancements of the element groups $\mathrm{CNO}, \mathrm{NeMgSi}$, and $\mathrm{Fe}$ for impulsive (filled symbols) and gradual (triangles) events, using different combinations of members of the NeMgSi group. Gradual events show a clear smooth correlation, while impulsive events show none. Both populations of events are related to the coronal, not the photospheric, abundances.

For impulsive events, however, the $\mathrm{Fe} / \mathrm{NeMgSi}$ and $\mathrm{NeMgSi} / \mathrm{CNO}$ ratios are obviously not correlated (Table 3 )! A larger enhancement of $\mathrm{NeMgSi}$ relative to $\mathrm{CNO}$ does not imply a larger enhancement of $\mathrm{Fe}$ relative to $\mathrm{NeMgSi}$ ! In addition, the spread on both the $\mathrm{NeMgSi} / \mathrm{CNO}$ and the $\mathrm{Fe} /$ $\mathrm{NeMgSi}$ ratio is surprisingly narrow, as if both of these ratios always kept roughly the same value, in all impulsive events! The statistical analysis indicates that $95 \%$ of the true $\mathrm{NeMgSi} /$ $\mathrm{CNO}$ and $\mathrm{Fe} / \mathrm{NeMgSi}$ enhancements lie within factors of $\sim 2.0$ and $\sim 1.5$ from their mean enhancements of $\sim 2.6$ and $\sim 2.8$ relative to coronal, respectively (Table 3 ). The similarity between these two mean enhancements is also striking, though it might well be coincidental.

\section{DISCUSSION}

\subsection{Comments on Theories of ${ }^{3} \mathrm{He}$ Enhancement}

One of the most prominent features of this study has been the large number of ${ }^{3} \mathrm{He}$-rich events that are seen, despite rather stringent selection criteria on the value of ${ }^{3} \mathrm{He} /{ }^{4} \mathrm{He}$ and on the number of particles required to provide adequate statis- tics. ${ }^{3} \mathrm{He}$-rich, Fe-rich energetic particles are seen in essentially all of the impulsive flare events for which ion acceleration is observed. The fact that the events are common places a new constraint on the theories of ${ }^{3} \mathrm{He}$ enhancement; unusual preexisting conditions in the corona are probably not involved. Thus, theories that require a large coronal $\mathrm{He} / \mathrm{H}$ ratio to generate electrostatic ion cyclotron waves above the ${ }^{4} \mathrm{He}$ gyrofrequency (Fisk 1978; Riyopoulos 1991) are incorrect unless He/ $\mathrm{H}$ enhancements are more common in the corona than is presently understood. Furthermore, there is apparently no relationship between the accelerated $\mathrm{H} / \mathrm{He}$ and ${ }^{3} \mathrm{He} /{ }^{4} \mathrm{He}$ ratios (Fig. 5).

Other theories of ${ }^{3} \mathrm{He}$ enhancements run into difficulties on different grounds. Winglee (1989) associates coronal evaporations with the wave generation that leads to abundance enhancements. However, none of the events in lists of coronal evaporation events (Antonucci, Gabriel, \& Dennis 1984) is associated with a ${ }^{3} \mathrm{He}$-rich event. Early theories involving ion acoustic waves (Ibragimov \& Kocharov 1977) have come under criticism on theoretical grounds (Weatherall 1984).

A recent theory by Temerin \& Roth (1992) uses electromag- 
netic hydrogen cyclotron waves to directly accelerate ${ }^{3} \mathrm{He}$. These waves are driven by streaming electrons like those that produce the type 1 III radio bursts which are systematically observed in these impulsive events (Reames et al. 1988). The waves propagate down the field lines until they reach field strengths where they resonate with the gyrofrequency of ${ }^{3} \mathrm{He}$ or the second harmonic of the gyrofrequencies of heavier ions. This acceleration mechanism is analogous to the process that produces "ion conics" observed in the Earth's aurorae. This mechanism is efficient at Alfvén speeds higher than $2000 \mathrm{~km}$ $\mathrm{s}^{-1}$, hence it is likely to occur fairly deep in the corona where the magnetic field is sufficiently high. Requirements on the number of ${ }^{3} \mathrm{He}$ particles in the larger events also suggest that acceleration occurs deep in the corona, as noted by Temerin \& Roth (1992) and discussed below. Miller \& Viñas (1993) have extended this work by examining all of the wave modes generated by streaming electrons. They suggest that ions with gyrofrequencies below that of ${ }^{4} \mathrm{He}(Q / A<0.5)$ resonate with a second type of unstable wave mode, shear Alfvén waves. Since ${ }^{3} \mathrm{He}$ and $\mathrm{Fe}$ resonate with different wave modes, no correlation of their enhancements would be expected. An important feature of these new theories is that ions can be accelerated to energies of several $\mathrm{MeV}$ amu ${ }^{-1}$ by the waves; earlier models provided only selective heating with the requirement of an additional (unspecified) mechanism of acceleration.

\subsection{Constraints on the Source Region}

Our ability to associate ${ }^{3} \mathrm{He}$-rich events with various electromagnetic emissions from impulsive flares already imposes constraints on the source region. As far as we can determine, all ${ }^{3} \mathrm{He}$-rich events are accompanied by type III radio bursts, indicating the presence of outward-streaming electrons. About $80 \%$ of the events have associated soft X-ray bursts, a similar fraction have $\mathrm{H} \alpha$ associations, and more than $50 \%$ have associated hard X-ray bursts. We assume that the particles that leave the Sun are accelerated on open field lines, first because most mechanisms of escape from closed loops would severely depress the low-energy spectra, contrary to observations, and second because acceleration mechanisms in modern theories (e.g., Temerin \& Roth 1992) work equally well in open and closed geometries. Since X-ray emission comes primarily from closed loops, our ability to associate with an X-ray event will depend upon the relative numbers of electrons accelerated on open and closed field lines in that particular event.

In some events the time-integrated fluence of ${ }^{3} \mathrm{He}$ particles above $1.3 \mathrm{MeV} \mathrm{amu}{ }^{-1}$ reaches $10^{5} \mathrm{~cm}^{-2}$, even though ${ }^{3} \mathrm{He} /$ ${ }^{4} \mathrm{He} \sim 1$. If these particles were emitted over a cone with a half-angle of $15^{\circ}$, a total of $10^{31}{ }^{3} \mathrm{He}$ nuclei would be required. If a flare occurs at a density of $10^{10}$ atoms $\mathrm{cm}^{-3}$ with an area of $10^{7} \mathrm{~km}^{2}$, a scale height of $10^{4} \mathrm{~km}$, and ${ }^{3} \mathrm{He} / \mathrm{H}=5 \times 10^{-5}$, then there are only $5 \times 10^{31}{ }^{3} \mathrm{He}$ ions in the flare volume. Since there are also ${ }^{3} \mathrm{He}$ ions below $1.3 \mathrm{MeV} \mathrm{amu}^{-1}$, the acceleration mechanism must be extremely efficient or the density and volume of plasma involved must be greater than generally believed, or both.

It is also possible that the average opening angle from the flare, over which energetic ions are observed, is much smaller than generally believed (Reames et al. 1991a). The observed longitude distribution of the impulsive events (Reames et al.
1990; Reames 1993 ) includes the random walk of the footpoint of the field line from the observer convolved with the mean opening angle from a single event. Nevertheless, it is unlikely that the mean cone half-angle is much less than about $5^{\circ}$, or ${ }^{3} \mathrm{He}$-rich events would be much more common on the solar disk than $\mathrm{H} \alpha$ flares or metric type III bursts. The ability to determine a flare longitude of a ${ }^{3} \mathrm{He}$-rich event depends upon observing an associated $\mathrm{H} \alpha$ flare. Unfortunately, during the last solar maximum, the ISEE 3 spacecraft had moved around the Sun, so that the longitudes of the most probable associated flares were not visible from Earth.

Given the paucity of ${ }^{3} \mathrm{He}$ ions in the source region it seems extremely unlikely that ${ }^{3} \mathrm{He}$-rich events are strongly associated with "high coronal flares" as suggested by Cliver \& Kahler (1991). These events are defined to occur 0.5 solar radii above the photosphere where densities are less than $10^{8}$ atoms $\mathrm{cm}^{-3}$. Most of the events we see have too much ${ }^{3} \mathrm{He}$ to be consistent with acceleration from such low densities. In the example that we considered above, a density of $10^{8}$ would imply that a single event could coherently deplete most the ${ }^{3} \mathrm{He}$ over an area of $10^{9} \mathrm{~km}^{2}$, an area comparable to that of a whole arcade of loops. Such large areas are not compatible with the associations of ${ }^{3} \mathrm{He}$-rich events and compact $\mathrm{H} \alpha$ flares (see Fig. 3 in Kahler et al. 1987). The need for sufficient ${ }^{3} \mathrm{He}$ and the need for a sufficient number of collisions to strip inner electrons from $\mathrm{Fe}$ ions are both satisfied in relatively dense regions. With the possible exception of a few small ${ }^{3} \mathrm{He}$-rich events seen early in the solar cycle (Reames et al. 1985), the events are reasonably well associated $(\sim 80 \%)$ with $\mathrm{X}$-ray and $\mathrm{H} \alpha$ flares (Reames et al. 1988; Reames et al. 1990) that involve strong chromospheric components. Hence, there is no evidence of bias toward phenomena that might only occur high in the corona. ${ }^{3} \mathrm{He}$-rich events appear to be democratically associated with all impulsive flares, including large gamma-ray-line flares (Van Hollebeke et al. 1990). In fact the abundances deduced from the broad gamma-ray lines indicate the same abundance enhancements for energetic ions in the flare loops as those in ${ }^{3}$ He-rich events (Murphy et al. 1991). Recently Benz et al. (1992) have discussed type III radio bursts at frequencies above $1 \mathrm{GHz}$ corresponding to electron beams at densities of $10^{10}-10^{11} \mathrm{~cm}^{-3}$. Perhaps these are the electron beams that produce the waves responsible for ion acceleration. Theoretically, the wave modes that resonate with ${ }^{3} \mathrm{He}$ to produce the enhancements (Temerin \& Roth 1992; Miller \& Viñas 1993) require conditions of high magnetic field that only occur near the base of the corona.

The smaller values of ${ }^{3} \mathrm{He} /{ }^{4} \mathrm{He}$ seen in very large impulsive events (Ramaty et al. 1980; Van Hollebeke et al. 1990) may be a direct result of depletion of ${ }^{3} \mathrm{He}$ in the source region rather than of a dilution of the first-phase material with shock-accelerated material with "normal" abundances. In the latter case, one would lower the Fe enhancement as well as the ${ }^{3} \mathrm{He} /{ }^{4} \mathrm{He}$ ratio, contrary to observations (Mason et al. 1986; Van Hollebeke et al. 1990). As additional energy is added in the source region, protons and ${ }^{4} \mathrm{He}$ eventually will be heated and accelerated despite a lower efficiency. In large impulsive events the situation is complicated by the presence of coronal shock waves, indicated by type II radio bursts, that may further accelerate the particles to the relatively high energies that are observed. The higher values of $\mathrm{H} /{ }^{4} \mathrm{He}$ in these events are reminis- 
cent of the similarly high ratios in gradual events, where shock acceleration predominates. The hard energy spectra in the large impulsive events (Van Hollebeke et al. 1990) are also different in character from those in smaller impulsive events (Reames, Richardson, \& Wenzel 1992), suggesting an additional mechanism at work. By confining our study to events with ${ }^{3} \mathrm{He} /{ }^{4} \mathrm{He}>0.1$, we do not sample these larger, more complex impulsive-flare events.

\subsection{Temperatures of the Gases from which the Heavy Ions Are Selected}

Virtually all of the mechanisms considered for ion enhancements and for acceleration depend upon the ion species through its magnetic gyrofrequency, and hence upon $Q / A$. Thus ion species with the same value of $Q / A$ cannot be enhanced relative to one another. One question, of course, is how different the values of $Q / A$ must be for measurable enhancement to occur. The dominant isotopes of $\mathrm{He}, \mathrm{C}, \mathrm{N}, \mathrm{O}, \mathrm{Ne}, \mathrm{Mg}$, $\mathrm{Si}$, and $\mathrm{S}$ all have $Z / A=0.5$, and thus enhancements could not take place if these ions were fully stripped. Furthermore, very abundant ions, especially $\mathrm{H}^{+}$and ${ }^{4} \mathrm{He}^{++}$, could strongly damp any waves near their gyrofrequencies. The width of the damping region depends upon the dispersion relation of the waves and upon the temperature of the ions through the ion-velocity dependence of the resonance condition (Miller \& Steinacker 1992; Steinacker et al. 1993).

Figure 14 shows the average $Q / A$ ratios of the dominant isotope of the observed elements versus temperature, as calculated at ionization equilibrium (after Arnaud \& Rothenflug 1985 and Arnaud \& Raymond 1992). The $Q / A$ ratio of each individual, discrete ionization state is indicated by a heavy dot,

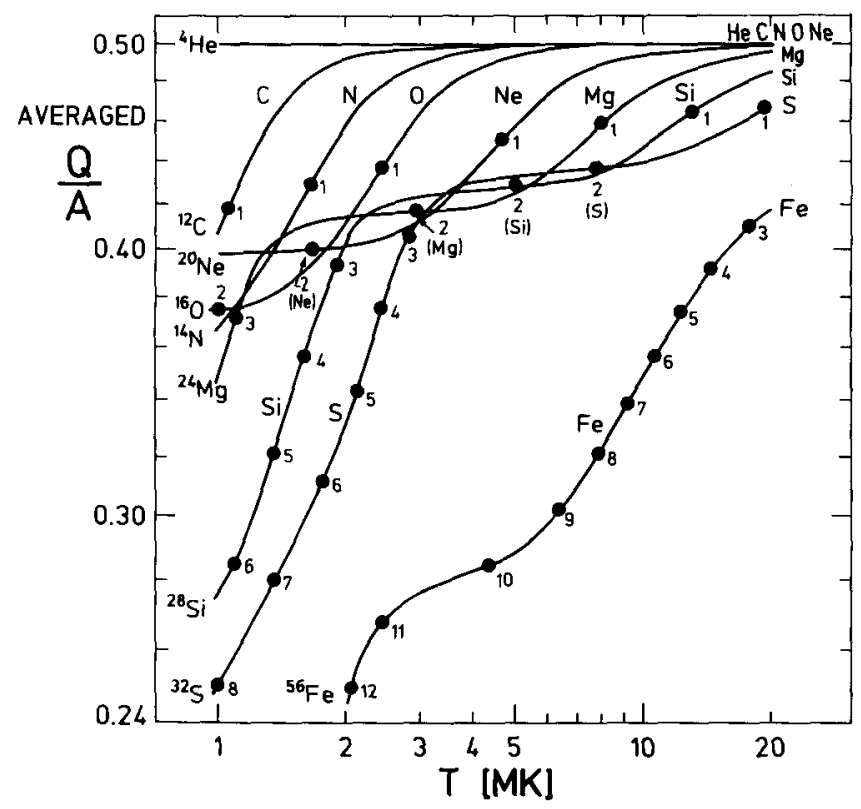

Fig. 14.-Average charge-to-mass ratio, $Q / A$, as a function of the plasma electron temperature (after Arnaud \& Rothenflug 1985 and Arnaud \& Raymond 1992). Filled circles mark the actual (integral) ionization states with the number of orbital electrons noted. The conspicuous plateaus near 2 and 10 orbital electrons reflect the stability of He-like and Ne-like configurations.

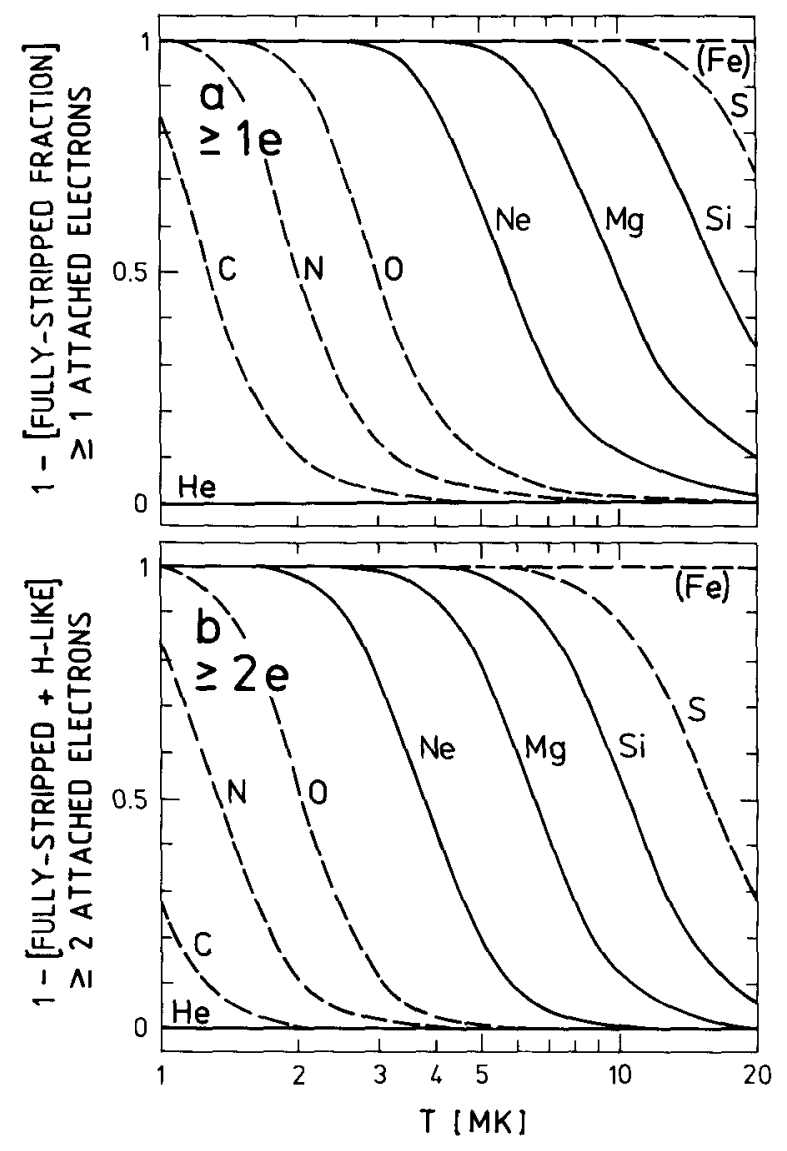

FIG. 15.-Probability that ions have at least $(a) 1$ or $(b) 2$ orbital electrons, shown as a function of the ambient electron temperature of the plasma.

whose abscissa is approximately the temperature at which its ionic fraction peaks. Figure $15 a$ shows the probability that ions have at least one orbital electron, as a function of the plasma electron temperature, and Figure $15 b$ shows the probability that ions have at least two orbital electrons. To allow a clearer discussion, we will sometimes label the ionization states by the number of attached electrons, e.g., " $0 e$ " for fully stripped, " $1 e$ " for H-like, " $2 e$ " for He-like, and so on, so that, for example, $\mathrm{Mg}^{+10} \equiv \mathrm{Mg}^{2 e}$.

Figures 14 and 15 show immediately (1) that ${ }^{4} \mathrm{He}$ and ${ }^{12} \mathrm{C}$ are essentially fully stripped, with $Q / A=0.5$, at all relevant coronal temperatures; (2) that beyond $\sim 10 \mathrm{MK}$ all elements up to $\mathrm{Ne}$, and, to a lesser degree $\mathrm{Mg}$, are essentially fully stripped; (3) that the He-like states ( $2 e$ ) of $\mathrm{Ne}, \mathrm{Mg}, \mathrm{Si}$, and $\mathrm{S}$ are very dominant over wide ranges of temperatures, as reflected in the broad plateaus of the average $Q / A$ ratios versus $T$ in Figure 14; this may play an important role in controlling the behavior of these elements; and (4) that for ${ }^{56} \mathrm{Fe} Q / A$ is always less than 0.5 ( since $Q / A \leq Z / A=0.464$ ), and that the $Q / A$ ratios of ${ }^{56} \mathrm{Fe}$ at all temperatures are very different from those of all the other observed elements, so that we can expect $\mathrm{Fe}$ to behave quite differently from lighter elements. Note that the He-like state $\mathrm{Fe}^{+24}$ is barely reached below $20 \mathrm{MK}$, and that the Ne-like state $(10 e) \mathrm{Fe}^{+16}$ predominates around $4 \mathrm{MK}$.

The lack of large enhancements of $\mathrm{O}$ relative to $\mathrm{C}$ ( compara- 
ble to those of NeMgSi; Figs. 8 and 9) implies that most of the selection took place in gases with temperatures above $\sim 3.5$ MK. Below that temperature, indeed, abundant non-fully stripped $\mathrm{O}^{\geq 1 e}$ would be available to yield a significant enhancement of $\mathrm{O} / \mathrm{C}$ (Figs. 14 and $15 a$ ). If we consider the possibility that $\mathrm{H}$-like $\mathrm{O}^{1 e}$ may not be enhanced because its $Q / A$ ratio of 0.438 is fairly close to 0.5 , then significant numbers of particles may be selected down to $\sim 2.5 \mathrm{MK}$ (Figs. 14 and $15 b$ ).

The very fact that $\mathrm{Ne}$ is enhanced at all implies that the selection largely takes place in gases where a significant fraction of $\mathrm{Ne}$ is not fully stripped, i.e., with temperature below $\sim 7 \mathrm{MK}$ (Fig. 15a). If $\mathrm{H}$-like $\mathrm{Ne}^{1 e}(Q / A=0.450)$ is also excluded, this upper bound to the required temperatures is shifted down to $\sim 5 \mathrm{MK}$ (Fig. $15 b$ ). The enhancements of $\mathrm{Ne}$, $\mathrm{Mg}$, and $\mathrm{Si}$ also tell us that their He-like states $(Q / A=0.400-$ 0.429 ) certainly do get enhanced, since these ions have $\leq 2$ electrons attached at reasonable coronal temperatures above 2 MK (Fig. 14).

Comparing the behaviors of $\mathrm{Ne}, \mathrm{Mg}$, and $\mathrm{Si}$ allows us to draw tighter limits to the allowed selection temperatures. Ne, $\mathrm{Mg}$, and $\mathrm{Si}$ are all found, on the average, to be enhanced by roughly equal factors of $\sim 2.5-3.5$ relative to $\mathrm{C}$ or $\mathrm{CNO}$, as compared with coronal abundances. In addition, the spreads both on these enhancements relative to $\mathrm{CNO}$ and on the various $\mathrm{Ne} / \mathrm{Mg} / \mathrm{Si}$ abundance ratios are quite small, with spread factors of $\sim 2$ and of $\sim 1.5$, respectively, for $95 \%$ of the events (Figs. 8, 10,11, and 13; Table 3 ).

Consider in particular the $\mathrm{Ne} / \mathrm{Si}$ ratio (Fig. $10 \mathrm{c}$ ). The fractions of non-fully stripped $\mathrm{Ne}^{z l e}$ and $\mathrm{Si}^{z l e}$ are very different for all temperatures above $\sim 5 \mathrm{MK}$ (Figs. 14 and $15 a$ ). Therefore, if a major fraction of the energetic $\mathrm{Ne}$ and $\mathrm{Si}$ ions were selected in gases with temperatures above $\sim 5 \mathrm{MK}$, one would expect $\mathrm{Ne}$ to be strongly depleted relative to $\mathrm{Si}$. This is totally at variance with observations (Fig. $10 c$; Table 3 ). Considering the possibility that $\mathrm{H}$-like $\mathrm{Ne}^{1 e}$ and $\mathrm{Si}^{1 e}$ (with similar $Q / A$ values of 0.450 and 0.464 ) may not be enhanced yields an even tighter constraint, since the fractions of $\mathrm{Ne}^{22 e}$ and $\mathrm{Si}^{\geq 2 e}$ are very different for all temperatures down to $\sim 3.5 \mathrm{MK}$ (Fig. $15 \mathrm{~b}$ ). On the other hand, the relative amounts of gas at different temperatures vary from flare to flare; if the selection took place within the flare gases over a wide range of temperatures, one would expect $\mathrm{Ne} / \mathrm{Si}$ to vary from event to event, but the observed spreads are all very limited (Fig. 10c; Table 3 ). One would then also expect an anticorrelation between the $\mathrm{Ne} / \mathrm{Mg}$ and $\mathrm{Si} / \mathrm{Mg}$ ratios (the richer the parent gas in higher temperature material, the lower $\mathrm{Ne} / \mathrm{Mg}$ and the higher $\mathrm{Si} / \mathrm{Mg}$ ); this anticorrelation is definitely not present in Figure 12. In brief, the large, very similar, and stable enhancements of $\mathrm{Ne}, \mathrm{Mg}, \mathrm{Si}$ relative to $\mathrm{CNO}$ tell us that most of these observed ions have been selected in gases below $\sim 5 \mathrm{MK}$ (or even below $3.5 \mathrm{MK}$, if $\mathrm{H}$-like ions are not selected).

We conclude (Table 4) that, if the $\mathrm{H}$-like ions $\mathrm{O}^{1 e}, \mathrm{Ne}^{1 e}$ and $\mathrm{Si}^{1 e}(Q / A=0.438-0.464)$ can all be selectively enhanced, the behaviors of $\mathrm{O} / \mathrm{C}$ and $\mathrm{Ne} / \mathrm{Si}$ require that species up to $\mathrm{Si}$ be selected entirely out of gases with temperatures between $\sim 3.5$ and $\sim 5 \mathrm{MK}$. If these $\mathrm{H}$-like ions do not get accelerated, the corresponding limits of the acceptable range are shifted down to $\sim 2.5$ to $\sim 3.5 \mathrm{MK}$. In any case, we have come to the conclusion that most particles of elements up to $\mathrm{Si}$ have been selected out of lower temperature gases somewhere in the
TABLE 4

CONSTRAINTS TO THE TEMPERATURE RANGes OF THE GaSES in Which the Selection Takes Place

\begin{tabular}{cccc}
\hline $\begin{array}{c}\text { Key Element } \\
\text { Ratios }\end{array}$ & $\begin{array}{c}\text { Key }(1 e) \text { ions } \\
{[Q / A]}\end{array}$ & $\begin{array}{c}\text { H-like (le) Ions } \\
\text { Enhanced }\end{array}$ & $\begin{array}{c}\text { H-like (le) Ions } \\
\text { Not Enhanced }\end{array}$ \\
\hline $\mathrm{O} / \mathrm{C} \ldots \ldots \ldots \ldots$ & $\mathrm{O}[0.438]$ & $>3.5 \mathrm{MK}$ & $>2.5 \mathrm{MK}$ \\
$\mathrm{Ne} / \mathrm{Si} \ldots \ldots \ldots \ldots$ & $\mathrm{Ne}[0.450]$ & $<5.0 \mathrm{MK}$ & $<3.5 \mathrm{MK}$ \\
$\mathrm{Combined} \ldots \ldots$ & $\mathrm{Si}[0.464]$ & $3.5-5.0 \mathrm{MK}$ & $2.5-3.5 \mathrm{MK}$ \\
\hline
\end{tabular}

$\sim 2.5$ to $\sim 5 \mathrm{MK}$ range. There are two possible explanations for this behavior:

1. If the selection mechanism can enhance the He-like states $\mathrm{Ne}^{2 e}, \mathrm{Mg}^{2 e}, \mathrm{Si}^{2 e}$ whatever the temperature, the selection must actually take place only from lower temperature gases, in the 2.5-5 MK range. These selection temperatures are comparable to, but distinctly higher than, the common quiescent active region temperatures of $\sim 2-3.5 \mathrm{MK}$ (Webb 1981; Bray et al. 1991; Saba \& Strong 1991a, b). Solar Maximum Mission $(S M M)$ observations suggest that elevated temperatures may be found commonly in active regions for up to an hour after a flare. There is also evidence for higher temperatures or a higher temperature component for an hour or so prior to some flares (Saba 1993).

2. The mechanism cannot enhance even the He-like states $\mathrm{Ne}^{2 e}, \mathrm{Mg}^{2 e}, \mathrm{Si}^{2 e}(Q / A=0.400-0.429)$ at higher temperatures because of temperature-dependent wave damping by ${ }^{4} \mathrm{He}$ (Miller \& Steinacker 1992; Steinacker et al. 1993). If these He-like states are rejected above some $\sim 3.5 \mathrm{MK}$, where $\mathrm{Ne}^{2 e}$ is low while $\mathrm{Mg}^{2 e}$ and $\mathrm{Si}^{2 e}$ are still predominant (Figs. 14 and $15 b)$, the $\mathrm{Ne} / \mathrm{Mg} / \mathrm{Si}$ ratios can be accounted for, even though the selection process continues at higher temperatures.

Now we consider Fe. Let us recall at this point that (1) the observed enhancements of $\mathrm{Fe} / \mathrm{CNO}$ are on the average much larger than those of $\mathrm{NeMgSi} / \mathrm{CNO}$ (factor of $\sim 7.5$ instead of $\sim 2.6$ ), (2) the enhancements of $\mathrm{Fe} / \mathrm{NeMgSi}$ are fairly stable ( $95 \%$ within a factor of $\sim 1.5$ from the mean), and uncorrelated with those of $\mathrm{NeMgSi} / \mathrm{CNO}$ (Table 3; Figs. 10 and $13 \mathrm{c}$ ). A priori, the selection of Fe need not be limited to the same temperature range as that of elements up to Si. However, it is simplest to assume that the selection takes place from an isothermal gas. The very low $Q / A$ ratio of $\mathrm{Fe}(\sim 0.290)$ as compared to $\mathrm{NeMgSi}(\sim 0.420)$ around $\sim 4 \mathrm{MK}$ (Fig. 14) may very well explain its higher mean enhancement, if the generated wave spectrum is more intense at lower frequencies, as predicted (Miller \& Viñas 1993). The small spread on the $\mathrm{Fe} / \mathrm{NeMgSi}$ ratio can then be understood if the shape of the wave frequency spectrum does not vary much from event to event. At the time of the selection, the predominant Fe charge state is then Ne-like $\mathrm{Fe}^{10 e}=\mathrm{Fe}^{+16}$ (Fig. 14).

It is possible that Fe ions, with much lower $Q / A$ 's than $\mathrm{NeMgSi}$ at all temperatures, are selected throughout a broad range of temperatures in the flaring gas. This might be another reason for the high $\mathrm{Fe}$ enhancement. However, the small spread on the $\mathrm{Fe} / \mathrm{NeMgSi}$ ratio would then seem more surprising. At temperatures above 10-15 MK, the highly stripped $\mathrm{Fe}^{\leq 5 e}=\mathrm{Fe}^{2+21}$ ions would have $Q / A$ ratios comparable to 
those of He-like $\mathrm{NeMgSi}$ and would no longer be selectively enhanced (Fig. 14).

\subsection{Second-Order Composition Anomalies}

We have shown in $\S 3.4$ that, to first order, the particles accelerated in impulsive (as well as gradual) events originate in a gas with coronal, not photospheric, composition. This was based mainly on the strikingly similar, ordered behaviors of high-FIP Ne and low-FIP Mg and Si when referred to coronal (gradual event) composition, as compared with their erratic behaviors when referred to photospheric composition ( $\mathrm{cf}$. Figs. $8,10,11,13$ ).

A more refined analysis, however, showed that, contrary to the low-FIP/low-FIP Si/Mg ratio which averages very closely $(1.11 \pm 0.14)$ to coronal abundances, the $\mathrm{Ne} / \mathrm{MgSi}$ ratio is on the average $1.46 \pm 0.18$ times coronal in impulsive events ( $\$ 3.6$, Fig. 11a, Table 3). This deviation from coronal abundance is not very large, but it is significant. The difference in the behavior of $\mathrm{Ne}$ as compared with $\mathrm{Mg}$ and $\mathrm{Si}$ is further supported by the higher $\chi^{2}$ found for a constant $\mathrm{Ne} / \mathrm{MgSi}$ $\left(\chi^{2}=1.25\right)$ than for a constant $\operatorname{Si} / \mathrm{Mg}\left(\chi^{2}=0.91\right)$. These $\chi^{2}$ values are consistent with a statistical spread for the $\mathrm{Si} / \mathrm{Mg}$ ratio but suggest an additional population spread by a factor of $\sim 1.42$ for $\mathrm{Ne} / \mathrm{MgSi}$ (see Table 3). The Ne overenhancement relative to $\mathrm{MgSi}$ could have two possible causes:

1. It might originate in the selective acceleration process itself, although this hypothesis does not seem very promising. The minor isotope of $\mathrm{Ne},{ }^{22} \mathrm{Ne}$, is less abundant than those of $\mathrm{Mg},{ }^{25,26} \mathrm{Mg}$, so large enhancements of rare isotopes would not help ( $\S 4.5)$. The non-fully stripped and non-H-like fractions of Ne can only be smaller than those of $\mathrm{Mg}$ and $\mathrm{Si}$ (Fig. 15). One might possibly imagine a higher enhancement of Ne because the $Q / A$ of $\mathrm{Ne}$ in its He-like state is slightly lower than those of $\mathrm{Mg}$ and $\mathrm{Si}(0.400,0.417$, and 0.429 ; Fig. 14); however, why would $\mathrm{Mg}$ and $\mathrm{Si}$ then behave so similarly? A resonant wave mode near the gyrofrequency of $\mathrm{Ne}$ could cause selective enhancement; however, no such wave mode is known. The generally smooth behavior of the heavy-element enhancements suggests substantial resonance broadening in this region.

2. Alternatively, the enhancement of $\mathrm{Ne}$ relative to $\mathrm{MgSi}$ could reflect a particular composition of the parent flare gas, in some way related to a peculiar FIP-dependent (ion-neutral) fractionation. It might imply that the FIP fractionation as a whole tends to be slightly weaker in the average flare gas available to impulsive events than in the upper corona and slow solar wind gas sampled by the gradual events ( which may well originate in specific narrow open-field structures squeezed between closed-loop systems at low altitude; Wang, Sheeley, \& Nash 1990; Meyer 1993a, b). Alternatively, it might reflect a specific enhancement of $\mathrm{Ne}$ in flare gases with otherwise coronal composition, as found in gamma-ray and X-ray observations of some large impulsive flares (Murphy et al. 1991; Murphy 1992; Schmelz \& Fludra 1993; Schmelz 1993; Saba \& Strong 1993; see also McKenzie \& Feldman 1992 and Meyer 1993a, b). Shemi ( 1991) has tentatively interpreted these high Ne abundances in terms of an ion-neutral fractionation following a specific $\mathrm{X}$-ray photoionization of $\mathrm{Ne}$ in a very dense medium (Meyer 1993a, b).
So it seems probable that the $\mathrm{Ne}$ enhancement relative to $\mathrm{MgSi}$, and its fluctuations, are due to variations in the composition of the parent gas, i.e., to ion-neutral fractionation taking place in different conditions. These variations may be related to the large observed spread on ${ }^{4} \mathrm{He} / \mathrm{C}$, which most likely also reflects variations in the parent gas composition ( $\S 3.2 ;$ Fig. 7). Note that limited variations of the $\mathrm{Ne} / \mathrm{Mg}$ ratios are observed even in gradual events, which sample the large-scale corona and interplanetary medium gas composition (Reames 1992).

The case of S, enhanced by an even larger factor of $1.81 \pm$ 0.32 relative to $\mathrm{MgSi}$ ( Fig. $11 b$; Table 3 ), is much less instructive, because several factors could cause its enrichment. At temperatures of $\sim 2.5-3 \mathrm{MK}, \mathrm{S}^{>4 e}$ becomes significant, with $Q / A$ ratios that are significantly lower than those of He-like $\mathrm{NeMgSi}$ (Fig. 14). Its abundance in the coronal gas is $\sim 5$ times lower than those of $\mathrm{NeMgSi}$, which might also influence its enhancement. Finally, $\mathrm{S}$ is an intermediate-FIP element (right at the borderline between those elements which are essentially ionized and those which are neutral in the region where the ion-neutral fractionation takes place), so that its behavior during ion-neutral fractionation taking place under slightly variable conditions cannot be easily predicted: it might possibly have an essentially photospheric abundance in the flare parent gas (e.g., Reames, Richardson, \& Barbier 1991b; von Steiger et al. 1992; McKenzie \& Feldman 1992; Meyer 1993a, b).

The reader should be aware that our abundance for a relatively rare element, like $S$, is affected somewhat by selection bias. To study the event-to-event variations in S, we have required statistically significant abundances. For small events, however, those with larger $\mathbf{S}$ abundances are preferentially selected over those with few or no $\mathrm{S}$ ions. The mean value of $\mathrm{S} / \mathrm{MgSi}$, averaged over all events, is actually $47 \%$ less than that deduced above from averaging only events with significant $S$. Thus the enhancement of S may not be as anomalously large as our results imply.

The apparent excess of $\mathrm{N}$ relative to $\mathrm{C}$ and $\mathrm{O}, \mathrm{N} / \mathrm{C}=1.52 \pm$ 0.34 , is not understood (Fig. 8; Table 3 ). Unlike $\mathrm{S} / \mathrm{MgSi}, \mathrm{N} / \mathrm{C}$ is probably less affected by selection bias.

\subsection{The Role of Minor Isotopes?}

Until now, we have primarily discussed the enhancements of the observed major elements, assuming that their dominant isotope in the gas $\left({ }^{20} \mathrm{Ne},{ }^{24} \mathrm{Mg},{ }^{28} \mathrm{Si},{ }^{56} \mathrm{Fe}\right)$ is still dominant among the accelerated particles.

Our conclusion that the $\mathrm{Ne}, \mathrm{Mg}, \mathrm{Si}$ ions cannot be selected in hot, higher than $10 \mathrm{MK}$ gases ( suggested by the observed Fe charge states) rested on the fact that their dominant isotopes in the fully stripped state have $Q / A=Z / A=0.5$. This is no longer true for the minor, heavier isotopes ${ }^{22} \mathrm{Ne},{ }^{25,26} \mathrm{Mg},{ }^{29,30} \mathrm{Si}$, which have $Q / A=Z / A<0.5$ even at the highest temperatures. More generally, at all temperatures they have $Q / A$ values significantly lower than those of ${ }^{20} \mathrm{Ne},{ }^{24} \mathrm{Mg}$, and ${ }^{28} \mathrm{Si}$. In addition, these isotopes are $\sim 10$ times less abundant than the predominant ones in the gas; the depletion of waves by excessive wave damping, if significant, would therefore be smaller at their gyroresonance frequencies than at those of ${ }^{20} \mathrm{Ne},{ }^{24} \mathrm{Mg}$, and ${ }^{28} \mathrm{Si}$. For all these reasons, it is conceivable that ${ }^{22} \mathrm{Ne}$, ${ }^{25,26} \mathrm{Mg}$, and ${ }^{29,30} \mathrm{Si}$ are more efficiently accelerated than ${ }^{20} \mathrm{Ne}$, ${ }^{24} \mathrm{Mg},{ }^{28} \mathrm{Si}$. 
Could the minor isotopes in the gas be overenhanced by such large factors $(z 10)$ that they are dominant among the accelerated $\mathrm{Ne}, \mathrm{Mg}$, and $\mathrm{Si}$ ions? (In that case our discussion in $\S 4.3$ would be irrelevant). The relative enhancements of $\mathrm{Ne}$, $\mathrm{Mg}$, and $\mathrm{Si}$ in the accelerated particles would then, to first order, reflect the relative fractions of heavier isotopes in the gas: ${ }^{22} \mathrm{Ne}, 6.8 \% ;{ }^{25} \mathrm{Mg}, 10.0 \% ;{ }^{26} \mathrm{Mg}, 11.0 \% ;{ }^{29} \mathrm{Si}, 4.7 \% ;{ }^{30} \mathrm{Si}$, 3.1\% (Anders \& Grevesse 1989 and references therein; Mewaldt \& Stone 1989; Cummings, Stone, \& Webber 1991). $\mathrm{Mg}$ would, in particular, probably be more enhanced than Si by a factor of $\sim 2-3$ (the lower $Q / A$ ratios of the $\mathrm{Mg}$ isotopes as compared with those of Si could only increase this effect). But it is observed that $\mathrm{Mg}$ and $\mathrm{Si}$ are enhanced, on the average, by the same factor within $\sim 20 \%$, with a small spread on the $\mathrm{Si}$ / $\mathrm{Mg}$ ratio (Fig. $10 \mathrm{a}$; Table 3 ). So a major role of the heavier isotopes seems unlikely.

It is of interest to note that the situation of the single-isotope odd- $Z$ elements ${ }^{23} \mathrm{Na}$ and ${ }^{27} \mathrm{Al}$ is very similar to that of ${ }^{22} \mathrm{Ne}$, ${ }^{25,26} \mathrm{Mg}$, and ${ }^{29,30} \mathrm{Si}$. They have $Z / A<0.5$, similar lower $Q / A$ ratios at all temperatures, and similar low abundances in the gas. In the absence of isotopic observations, measurements of the $\mathrm{Na}$ and $\mathrm{Al}$ elemental abundances may therefore allow a rough estimate of the (possibly enhanced) contributions of the $\mathrm{Ne}, \mathrm{Mg}$, and $\mathrm{Si}$ heavier isotopes. They may also allow us to estimate the significance of saturation of wave damping by species like ${ }^{20} \mathrm{Ne},{ }^{24} \mathrm{Mg}$, and ${ }^{28} \mathrm{Si}$ with abundances of $\sim 10^{-4}$ of H (Steinacker et al. 1993).

\subsection{The Problem of Observed Charge States}

Klecker et al. (1984) and Luhn et al. (1987) have provided observations of the charge states $Q$ of energetic $\mathrm{He}, \mathrm{Si}$, and $\mathrm{Fe}$ in ${ }^{3} \mathrm{He}$-rich events. As judged from the consistent picture provided by the charge states obtained in gradual events with the same instrument (Luhn et al. 1984, 1985), no large systematic error on the charge scales is expected. These observations indicate that $\mathrm{He}$ is, as expected, fully stripped.

The Si observations, peaking around $Q \approx 14$, suggest that $\mathrm{Si}$ is also essentially fully stripped in ${ }^{3} \mathrm{He}$-rich events. This latter conclusion may, however, be not entirely safe, in view of the limited statistics and of the very poor charge resolution: seven out of the $13 \mathrm{Si}$ counts yield charges $Q>Z=14$, with counts up to $Q=21$. Note that the associated equilibrium gas temperature is highly sensitive to the exact charge state, because the He-like state is dominant over a very wide range of temperatures. While a predominance of fully stripped $\mathrm{Si}^{+14}$ implies $T \gtrsim 16 \mathrm{MK}$, a predominance of $\mathrm{He}$-like $\mathrm{Si}^{+12}$ is consistent with any temperature all the way from $\sim 10$ down to $\sim 2$ MK (Arnaud \& Rothenflug 1985; see Fig. 14 of this paper).

The data of Luhn et al. (1987) on Fe show a peak at charges $Q=21-24$ with a mean value of $20.5 \pm 1.2$ (95\% confidence). The unsymmetrical shape of the observed distribution suggests a real contribution of lower charge states. There seems to be a larger probability of having $Q \geq 21\left(\mathrm{Fe}^{55 e}\right)$, corresponding to $T \gtrsim 10 \mathrm{MK}$, than of having $15 \leq Q<20$, corresponding to $T \sim$ 2-10 MK (Arnaud \& Raymond 1992; Fig. 14). The data, indeed, suggest that charge states beyond $Q=24\left(\mathrm{Fe}^{\leq 2 e}\right)$ might never be reached, i.e., that, while several L-shell electrons are commonly stripped, K-shell ones are usually not (indeed, they are stripped only beyond $\sim 50 \mathrm{MK}$ ). By contrast to $\mathrm{Si}$, the charge state of $\mathrm{Fe}$ varies rapidly with temperature (Fig. 14), so that the Fe charge state is a good "thermometer."

Thus we have a clear conflict between the temperatures and ionization states that we deduced from the abundances and those from the direct observations of the energetic ions. In fact, if the observed charge state, $Q=Z$, of elements up to Si existed at the time of ion selection and acceleration, there could be no enhancements of $\mathrm{Ne}, \mathrm{Mg}$, or $\mathrm{Si}$ with respect to ${ }^{4} \mathrm{He}, \mathrm{C}, \mathrm{N}$, and $\mathrm{O}$. Furthermore, the observed charge state of $\mathrm{Fe}$ suggests a temperature higher than $10 \mathrm{MK}$ rather than $\sim 3.5 \mathrm{MK}$.

We can reconcile this apparent contradiction, however, by assuming that the ions are further ionized during or after acceleration. Three processes can tentatively be considered:

1. The possibility of stripping by matter traversal of energetic ions was considered by Luhn \& Hovestadt (1987). The Fe ions were observed by Luhn et al. (1987) in the range 0.34$1.8 \mathrm{MeV} \mathrm{amu}^{-1}$, corresponding to velocities of $(0.8-1.9) \times$ $10^{9} \mathrm{~cm} \mathrm{~s}^{-1}$ (most of the ions are presumably near the lowest velocity). These Fe velocities are equal to the rms velocities of thermal electrons between 1.4 and $8.0 \mathrm{MK}$. At such temperatures the significant $\mathrm{Fe}$ charge states range from $\mathrm{Fe}^{+11}$ to $\mathrm{Fe}^{+19}$ at thermal equilibrium (Arnaud \& Raymond 1992; actually, even lower temperatures should be considered, since at equilibrium the electrons in the tail of the thermal distribution play a key role in the ionization); these are roughly the equilibrium charge states reached by $0.34-1.8 \mathrm{MeV} \mathrm{amu}^{-1} \mathrm{Fe}$ ions traversing a cool gas. But the observed charge states lie predominantly beyond $\mathrm{Fe}^{+21}$, i.e., they are higher than these fast-Fe equilibrium charge states. Stripping due to the high velocity of the accelerated ions therefore cannot account for the observed charge states.

2. Another possibility is that the particles are selected and accelerated fairly early in the flare process, but remain trapped in the flaring loop sufficiently long that the gas is heated to temperatures $\geq 10 \mathrm{MK}$ and the ions come to charge equilibrium with the hot electrons. The timescales for acceleration of electrons and ions $(\sim 10 \mathrm{~s})$ are less than the timescales of the hard X-ray and gamma-ray bursts (typically $\leq 1$ minute), respectively, and these are substantially less than the heating timescale defined by the soft X-rays in impulsive events (Dennis 1985; Reames et al. 1988; Chupp 1990). The gamma rays are produced by ions that have been accelerated on closed loops and are scattered into the loss cone so as to interact in the lower solar atmosphere. Thus, even the ions on closed loops are not present for long. The ions seen at $1 \mathrm{AU}$ are likely to have been accelerated on nearby open magnetic fields; they stream out from the Sun after dissipation of the waves that accelerate and detain them (Reames 1990). These ions, like the associated electrons that produce the type III burst, only remain near the Sun for $\sim 10-20 \mathrm{~s}$. Electron heating (in a collisionless plasma) seems too slow to alter the ionization states of the ions significantly.

3. The strong observational association of ${ }^{3} \mathrm{He}$-rich events with electron beams and type III bursts (Reames et al. 1985; Reames \& Stone 1986; Reames et al. 1988) and the recent theories that suggest that the ion enhancements are a consequence of electron-beam-generated waves (Temerin \& Roth 1992; Miller \& Viñas 1993) suggest the possibility of ionization by the electrons of the beam itself. For the conditions of 
their model, Miller \& Viñas ( 1993) conclude that Fe will reach an equilibrium charge state of $\mathrm{Fe}^{+19}$ in $10 \mathrm{~s}$ when bombarded by $5 \mathrm{keV}$ electrons with a density equal to $10 \%$ of the ambient electron density. This is comparable to the acceleration time of these ions. This charge state is not quite high enough to account for the maximum observed charge states, somewhere near $\mathrm{Fe}^{+21}$, but the sensitivity of the equilibrium charge state to the parameters of the model, e.g., the beam energy, has not been investigated. Ions such as $\mathrm{Ne}, \mathrm{Mg}$, and $\mathrm{Si}$ would be completely ionized by the beam during and after acceleration, in agreement with charge-state observations at 1 AU. This scenario holds the promise of a beautifully self-consistent picture of the abundance enhancements and ionization states.

\section{SUMMARY}

The anomalous abundances of energetic ions that we characterize as ${ }^{3} \mathrm{He}$-rich and $\mathrm{Fe}$-rich are a common phenomenon in impulsive solar flares. The sensitivity of the present instruments allows us to observe ions from events corresponding to $\sim 1000$ events $\mathrm{yr}^{-1}$ on the visible disk at solar maximum and at least a factor of 50 fewer at solar minimum. The number of ${ }^{3} \mathrm{He}$ ions in large events requires acceleration of more than $10 \%$ of the ${ }^{3} \mathrm{He}$ ions present in a typical flare volume of $10^{11} \mathrm{~km}^{3}$ at a density of $10^{10} \mathrm{H}$ atoms $\mathrm{cm}^{-3}$, implying highly efficient selective acceleration near the base of the corona. The ions always accompany the $\sim 10 \mathrm{keV}$ electron beams that produce type III radio bursts, and recent theories suggest that the ions are accelerated by resonant interactions with electromagnetic plasma waves generated by these streaming electrons.

The degrees of enhancement of ${ }^{3} \mathrm{He}$ and heavy ions like $\mathrm{Fe}$ are vastly different. In the solar corona the abundance of $\mathrm{Fe}$ is only about 5 times that of ${ }^{3} \mathrm{He}$; in the accelerated particles, ${ }^{3} \mathrm{He} /{ }^{4} \mathrm{He}$ has been enhanced by factors $\sim 10^{3}$ or $10^{4}$, while $\mathrm{Fe} /{ }^{4} \mathrm{He}$ has been enhanced by a factor of less than 10 . Furthermore, the ${ }^{3} \mathrm{He}$ and heavy-ion enhancements are uncorrelated.
This suggests that the ions interact with two different wave modes (Miller \& Viñas 1993); electromagnetic hydrogen ion cyclotron waves are produced near the gyrofrequency of ${ }^{3} \mathrm{He}$, while shear Alfvén waves are produced below the ${ }^{4} \mathrm{He}$ gyrofrequency and resonate with the heavier ions.

In the first-order comparison of the abundances with coronal composition, ${ }^{4} \mathrm{He}, \mathrm{C}, \mathrm{N}$, and $\mathrm{O}$ are relatively unenhanced while $\mathrm{Ne}, \mathrm{Mg}$, and $\mathrm{Si}$ are enhanced by a factor $\sim 2.5$ and $\mathrm{Fe}$ by a factor of 7 . We interpret this pattern in terms of the temperature of the preflare plasma. In the temperature region $\sim 3.5$ MK, ions in the first group are all fully ionized, or nearly so, and thus they all have $Q / A \sim 0.5$. $\mathrm{Ne}, \mathrm{Mg}$, and $\mathrm{Si}$ are all on a He-like plateau of $Q / A \sim 0.43$, and thus they resonate with the same waves and obtain a similar enhancement. Fe has $Q / A \sim 0.28$ in this region and has a larger enhancement. Temperatures of $\sim 3 \mathrm{MK}$ are quite typical of ordinary active regions, and $\sim 4 \mathrm{MK}$ is typical of preflare active regions. It is likely that ${ }^{4} \mathrm{He}$ and all of the heavy ions couple to the shear Alfvén mode, perhaps by resonance broadening from variations in the magnetic field, because all of their abundances are closely coupled and vary smoothly with species.

The ion charge states near $3.5 \mathrm{MK}$, e.g., $\mathrm{Fe}^{+16}$, are much lower than those observed in the accelerated particles at $1 \mathrm{AU}$, $\mathrm{Fe}^{+20.5}$. A self-consistent explanation may be that the particles are stripped during and after acceleration by the same electron beam that produced the waves.

The authors would like to thank J. A. Miller for his comments on the manuscript. We would also like to thank Uri Feldman, Julia Saba, Joan Schmelz, and Ken Widing for discussions on the active region temperatures. We are indebted to G. Fasano and R. Vio for providing their computer code for linear regression with errors on both coordinates, which served as a starting point for the code we developed. J. P. M. acknowledges receipt of a National Research Council-GSFC Senior Research Associateship.

\section{REFERENCES}

Anders, E., \& Grevesse, N. 1989, Geochim. Cosmochim. Acta, 53, 197

Antonucci, E., Gabriel, A. H., \& Dennis, B. R. 1984, ApJ, 287, 917

Arnaud, M., \& Raymond, J. 1992, ApJ, 398, 394

Arnaud, M., \& Rothenflug, R. 1985, A\&AS, 60, 425

Benz, A. O., Magun, A., Stehling, W., \& Su, H. 1992, Sol. Phys., 141, 335

Bray, R. J., Cram, L. E., Durrant, C. J., \& Loughhead, R. E. 1991, Plasma

Loops in the Solar Corona (Cambridge: Cambridge Univ. Press)

Breneman, H., \& Stone, E. C. 1985, ApJ, 299, L57

Cane, H. V., Reames, D. V., \& von Rosenvinge, T. T. 1991, ApJ, 373, 675

Chupp, E. L. 1990, ApJS, 73, 213

Cliver, E., \& Kahler, S. 1991, ApJ, 366, L91

Cummings, A. C., Stone, E. C., \& Webber, W. R. 1991, Proc. 22 d Int. Cosmic Ray Conf. (Dublin), 3, 362

Dennis, B. R. 1985, Sol. Phys., 100, 465.

Dennis, B. R., Orwig, L. E., Kennard, G. S., Labow, G. J., Schwartz, R. A.

Shaver, A. R., \& Tolbert, A. K. 1991, The Complete Hard X-Ray Burst Spectrometer Event List, 1980-1989 (NASA TM-4332)

Fasano, G., \& Vio, R. 1988, Newsletter Working Group Mod. Astron. Meth., 7, 3

Feldman, U., \& Widing, K. G. 1990, ApJ, 363, 292

Fisk, L. A. 1978, ApJ, 224, 1048

Grevesse, N., Lambert, D. L., Sauval, A. J., van Dishoeck, E. F., Farmer,

C. B., \& Norton, R. H. 1990, A\&A, 232, 225 1991, A\&A, 242, 488

Grevesse, N., \& Noels, A. 1993, in Origin and Evolution of the Elements, ed. N. Prantzos, E. Vangioni-Flam, \& M. Cassé (Cambridge: Cambridge Univ. Press), in press
Hsieh, K. C., \& Simpson, J. A. 1970, ApJ, 162, L191

Hurford, G. J., Mewaldt, R. A., Stone, E. C., \& Vogt, R. E. 1975, ApJ, 201, L95

Ibragimov, I. A., \& Kocharov, G. E. 1977, Proc. 15th Int. Cosmic Ray Conf. (Plovdiv), 11, 340

Kahler, S. W. 1992, ARA\&A, 30, 113

Kahler, S. W., Lin, R. P., Reames, D. V., Stone, R. G., \& Liggett, M. 1987, Sol. Phys., 107, 385

Kahler, S. W., Reames, D. V., Sheeley, N. R., Jr., Howard, R. A., Koomen M. J., \& Michels, D. J. 1985, ApJ, 290, 742

Kahler, S. W., Sheeley, N. R., Jr., Howard, R. A., Koomen, M. J., Michels, D. J., McGuire, R. E., von Rosenvinge, T. T., \& Reames, D. V. 1984, J. Geophys. Res., 12, 209

Klecker, B., Hovestadt, D., Gloeckler, G., Ipavich, F. M., Scholer, M., Fan, C. Y., \& Fisk, L. A. 1984, ApJ, 281, 458

Kocharov, L. G., \& Kocharov, G. E. 1984, Space Sci. Rev., 38, 89

Lampton, M., Margon, B., \& Bowyer, S. 1976, ApJ, 208, 177

Luhn, A., \& Hovestadt, D. 1987, ApJ, 317, 852

Luhn, A., et al. 1985, Proc. 19th Int. Cosmic Ray Conf. (La Jolla), 4, 241

Luhn, A., Klecker, B., Hovestadt, D., Gloeckler, G., Ipavich, F. M. Scholer, M., Fan, C. Y., \& Fisk, L. A. 1984, Adv. Space Res., 4 (Nos. 2-3), 161

Luhn, A., Klecker, B., Hovestadt, D., \& Möbius, E. 1987, ApJ, 317, 951

Mason, G. M., Fisk, L. A., Hovestadt, D., \& Gloeckler, G. 1980, ApJ, 239 1070

Mason, G. M., Gloeckler, G., \& Hovestadt, D. 1979, ApJ, 281, L87

Mason, G. M., Ng, C. K., Klecker, B., \& Green, G. 1989, ApJ, 339, 529 
Mason, G. M., Reames, D. V., Klecker, B., Hovestadt, D., \& von Rosenvinge, T. T. 1986, ApJ, 303, 849

McKenzie, D. L., \& Feldman, U. 1992, ApJ, 389, 764

Melrose, D. B. 1990 , Australian J. Phys., 43, 703

Mewaldt, R. A., \& Stone, E. C. 1989, ApJ, 337, 959

Meyer, J. P. 1985a, ApJS, 57, 151 . 1985b, ApJS, 57, 173

1989, in AIP Conf. Proc. 183, Cosmic Abundances of Matter, ed.

C. J. Waddington (New York: AIP), 245

1991, Adv. Space Res., 11 (No. 1), 269

- 1993a, in Origin and Evolution of the Elements, ed. N. Prantzos, E. Vangioni-Flam, \& M. Cassé (Cambridge: Cambridge Univ. Press), in press

- 1993 b, Adv. Space Res., 13 (No. 9), 377

Miller, J. A., \& Steinacker, J. 1992, ApJ, 399, 284

Miller, J. A., \& Viñas, A. F. 1993, ApJ, 412, 386

Murphy, R. J. 1992, private communication

Murphy, R. J., Ramaty, R., Kozlovsky, B., \& Reames, D. V. 1991, ApJ, 371, 793

Pallavicini, R., Serio, S., \& Vaiana, G. 1977, ApJ, 216, 108

Ramaty, R., et al. 1980, in Solar Flares: A Monograph from the Skylab Solar Workshop II, ed. P. A. Sturrock (Boulder: Colorado Assoc. Univ. Press), 117

Reames, D. V. 1990, ApJ, 73, 235

— 1992, in First SOHO Workshop on Coronal Streamers, Coronal Loops, and Coronal and Solar Wind Composition, ed. V. Domingo (ESA SP-348; Paris: ESA), 315

_- 1993, Adv. Space Res., 13 (No. 9), 331

Reames, D. V., Cane, H. V., \& von Rosenvinge, T. T. 1990, ApJ, 357, 259 Reames, D. V., Dennis, B. R., Stone, R. G., \& Lin, R. P. 1988, ApJ, 327, 998

Reames, D. V., Kallenrode, M. B., \& Stone, R. G. 1991a, ApJ, 380, 287

Reames, D. V., Richardson, I. G., \& Barbier, L. 1991 b, ApJ, 382, L43

Reames, D. V., Richardson, I. G., \& Wenzel, K. P. 1992, ApJ, 387, 715

Reames, D. V., \& Stone, R. G. 1986, ApJ, 308, 902
Reames, D. V., \& von Rosenvinge, T. T. 1981, Proc, 17th Int. Cosmic Ray Conf. (Paris), 3, 162

Reames, D. V., von Rosenvinge, T. T., \& Lin, R. P. 1985, ApJ, 292, 716

Riyopoulos, S. 1991, ApJ, 381, 578

Rubin, R. H., Simpson, J. P., Haas, M. R., \& Erickson, E. F. 1991, ApJ, 374,564

Saba, J. L. R. 1993, private communication

Saba, J. L. R., \& Strong, K. $1991 \mathrm{a}$, ApJ, 375, 789

1991 b, Adv. Space Res. 11 (No. 1), 126

1993, Adv. Space Res., 13 (No. 9), 391

Schmelz, J. T. 1993, ApJ, 408, 373

Schmelz, J. T., \& Fludra, A. 1993, Adv. Space Res., 13 (No. 9), 325

Sheeley, N. R., Jr., et al. 1975, Sol. Phys., 45, 377

Sheeley, N. R., Jr., Stewart, R. T., Robinson, R. D., Howard, R. A., Koomen, M. J., \& Michels, D. J. 1984, ApJ, 279, 839

Shemi, A. 1991, MNRAS, 251, 221

Steinacker, J., Meyer, J. P., Campeanu, A., Miller, J. A., \& Reames, D. V. 1993, in preparation

Stone, E. C. 1989, in AIP Conf. Proc. 183, Cosmic Abundances of Matter, ed. C. J. Waddington (New York: AIP), 72

Temerin, M., \& Roth, I. 1992, ApJ, 391, L105

Van Hollebeke, M. A. I., McDonald, F. B., \& Meyer, J. P. 1990, ApJ, 73, 285

von Rosenvinge, T. T., McDonald, F. B., Trainor, J. H., Van Hollebeke, M. A. I., \& Fisk, L. A. 1978, IEEE Trans., GE-16, 208

von Steiger, R., Christon, S. P., Gloeckler, G., \& Ipavitch, F. M. 1992, ApJ, 389, 791

Wang, Y. M., Sheeley, N. R., \& Nash, A. G. 1990, Nature, 347, 439

Wayman, P. A. 1959 , Nature, 184,77

Weatherall, J. 1984, ApJ, 281, 468

Webb, D. F. 1981, in Solar Active Regions, ed. F. Q. Orrall (Boulder: Univ. Colorado Press), 165

Widing, K. G., Feldman, U., \& Bhatia, A. K. 1986, ApJ, 308, 982

Winglee, R. M. 1989, ApJ, 343, 511 